Research papers

\title{
Evaluating soil evaporation parameterizations at near-instantaneous scales using surface dryness indices
}

\author{
Yanchun Gao ${ }^{\mathrm{b}}$, Guojing Gan ${ }^{\mathrm{a}, \mathrm{b}, \mathrm{c}, *}$, Maofeng Liu ${ }^{\mathrm{d}}$, Jinfeng Wang ${ }^{\mathrm{b}, \mathrm{c}}$ \\ ${ }^{a}$ Key Laboratory of Watershed Geographic Sciences, Nanjing Institute of Geography and Limnology, Chinese Academy of Sciences, Nanjing 21008, China \\ ${ }^{\mathrm{b}}$ Key Laboratory of Water Cycle and Related Land Surface Processes, Institute of Geographical Sciences and Natural Resources Research, Chinese Academy of Sciences, Beijing \\ 100101, China \\ ${ }^{\mathrm{c}}$ University of the Chinese Academy of Sciences, Beijing 100049, China \\ ${ }^{\mathrm{d}}$ Department of Civil and Environmental Engineering, Princeton University, Princeton, NJ, United States
}

\section{A R T I C L E I N F O}

\section{Article history:}

Received 29 June 2015

Received in revised form 10 August 2016

Accepted 14 August 2016

Available online 16 August 2016

This manuscript was handled by $\mathrm{K}$.

Georgakakos, Editor-in-Chief, with the

assistance of Venkat Lakshmi, Associate

Editor

\section{Keywords:}

Soil evaporation

TSEB

Relative evaporation

Surface dryness index

MODIS LST

\begin{abstract}
A B S T R A C T
Soil evaporation is an important component in the water and energy cycles on land, especially for areas that are moderately or densely covered by bare soil. Soil evaporation parameterizations that scale down potential evaporation with the soil surface temperature $\left(T_{\mathrm{s}}\right)$ and/or the air humidity are regionally applicable because of the advantage of omitting pixel-scale near-surface soil moisture. In this paper, we provide an intercomparison study among these parameterizations. Potential evaporation indices are estimated from the Priestley-Taylor method, the Penman method, and the mass transfer method (with or without $T_{\mathrm{s}}$ ). The surface dryness indices that indicate the water availability of the soil surface are based on $T_{\mathrm{s}}$ and/or the air humidity. We establish and evaluate ten such soil evaporation parameterizations through combinations of different types of potential evaporation indices and surface dryness indices at near-instantaneous scales ( $30 \mathrm{~min}$ ). The results show that incorporating the soil temperature in the surface dryness index instead of the potential evaporation index can improve soil evaporation estimations. Poorer but still reasonable estimations are achieved when only the air humidity-based surface dryness index is used. In addition, the energy balance factor is crucial in the surface dryness indices. Our study indicates that the potential evaporation indices that are based on the Penman equation are generally more useful and robust than those that are based on the Priestley-Taylor approach or the mass transfer method. However, when the surface dryness index is only based on air humidity data, the PriestleyTaylor potential evaporation index performs as well as the index that is estimated from the Penman equation. In contrast, a soil evaporation parameterization that estimates the potential evaporation through the mass transfer method (with $T_{\mathrm{s}}$ ) and the surface dryness index from the soil moisture content did not perform as well as the above ten parameterizations.
\end{abstract}

(c) 2016 Elsevier B.V. All rights reserved.

\section{Introduction}

Evapotranspiration (ET), which includes evaporation from soil and water and transpiration from plants, is a major component in the land surface water cycle and energy balance (Oki and Kanae, 2006; Trenberth et al., 2009, 2007). The spatial estimation of daily ET, especially its partitioning between the canopy and soil layers is therefore useful to improve irrigation design (Colaizzi et al., 2004), climate simulations (Lawrence et al., 2007) and

\footnotetext{
* Corresponding author at: Key Laboratory of Watershed Geographic Sciences, Nanjing Institute of Geography and Limnology, Chinese Academy of Sciences, Nanjing 21008, China.

E-mail addresses: gaoyanc@igsnrr.ac.cn (Y. Gao), ganguojing10@gmail.com (G. Gan).
}

environmental assessments (Newman et al., 2006). Transpiration at daily or smaller time scales has been successfully estimated by using remote-sensing based vegetation indices (VIs) and physiological canopy conductance models (Gan and Gao, 2015; Leuning et al., 2008; Mu et al., 2011; Zhang et al., 2010). However, estimating soil evaporation is more complicated and less constrained compared to transpiration calculations, which may cause great estimation errors in moderately and sparsely vegetative areas.

Evaporation at remote-sensing-pixel scales is usually estimated by tuning down the potential rate of evaporation with the soil moisture availability at the near suface. For example, the Penman hypothesis assumes that the actual evaporation is proportional to the potential evaporation, and one method to estimate the relative evaporation $\mathrm{LE} / \mathrm{LE}$, where $\mathrm{LE}$ and $\mathrm{LE}_{\mathrm{p}}$ are the actual and potential ET, respectively, is introducing a function of soil water availability 
(Yang et al., 2006). However, the operational retrievals of regional soil moisture at moderate resolution (approximately $1 \mathrm{~km}$ ) remain a challenge even with the great development of microwave remote sensing techniques because passive microwave systems measure the soil moisture at relatively coarse resolution (e.g., $25 \mathrm{~km}$ ) and active microwave systems require local calibration to minimize the effects of vegetation and surface roughness on radar signals (Wagner et al., 2007). In addition, the surface soil moisture may experience rapid changes over short time scales, so the difficulty of this method is further highlighted at near-instantaneous scales (e.g., $30 \mathrm{~min}$ in this study).

A possible way to avoid using the pixel-scale soil moisture content is to estimate the actual ET directly from the potential ET. For example, Bouchet (1963) stated that the actual ET is not necessarily proportional to the potential ET; in contrast, as the surface dries, a decrease in the actual ET is accompanied by an identical increase in the potential ET if the total available energy is constant. This is known as the complementary relationship. Thus the actual ET can be readily estimated from the potential ET by using such complementary models (Brutsaert and Stricker, 1979; Granger, 1989a; Morton, 1983). However, such models usually require a hypothesis on the exact relationship between the changes in the energy that is used in the actual ET and the energy that is available for the potential ET, which may not be valid in all spatial and temporal scales.

Another way to directly estimate the actual ET from the potential ET is to return to the relative evaporation perspective but explore the usage of potential evaporation in indicating the surface dryness. The actual evaporation is estimated as the product of the potential evaporation and the relative evaporation, and the latter is estimated from the surface dryness index (SDI), which is parameterized as a function of the potential ET. The key of such parameterizations is to model the SDI from the potential evaporation.

Granger and Gray (1989) modeled the SDI as a dimensionless index that combines the available energy at the land surface and the drying power of the air. The drying power of the air is an index that indicates the potential ET and is estimated from the mass transfer method by using the air humidity. The air humidity is influenced by land-atmosphere feedbacks through ET (Brutsaert and Stricker, 1979), and thus reflects the surface dryness to some extent (Granger and Gray, 1989). Compared to the soil moisture, the air humidity is a more readily available variable that can be obtained from weather station measurements or regional atmospheric simulations. However, the coupling between the atmospheric humidity and the near-surface soil moisture deviates from the equilibrium state because of the large-scale advection effect, in which case the atmospheric humidity is no longer a good indicator of the near-surface soil moisture content.

Compared to the air humidity, the soil surface temperature is more directly linked to the near surface soil moisture conditions. This factor can be used to scale down the potential evaporation to estimate the actual evaporation, for example, within the LSTVI framework (Long and Singh, 2012; Merlin et al., 2014; Nishida et al., 2003) and the PT-JPL model (Garcia et al., 2013), which was first proposed by Fisher et al. (2008). In addition, a potential evaporation index can be estimated by using the mass transfer method with the land surface temperature thanks to the development of thermal remote sensing techniques. Crago and Crowley (2005) compared several versions of complementary ET models that use different combinations of potential ET indices (with and without land surface temperature) at near-instantaneous time scales. However, their models were applied to estimates the total ET instead of the soil evaporation.

In this study, we focus on the parameterization of soil evaporation. We attempt to directly establish the relationships between the relative evaporation and the surface dryness indices for different situations with different data availability by using model sim- ulations and in-situ measurements. First, we incorporate the land surface temperature (LST) in potential evaporation indices and surface dryness indices and then determine the best incorporation method by comparing the strength of six combinations of potential evaporation indices and surface dryness indices when estimating the soil evaporation. Such formulations can be useful in diagnostic and process-based models, in which energy fluxes and the LST are simultaneously determined. Second, we evaluate the usage of air humidity data in estimating the near-instantaneous soil evaporation and determine the best formulation out of four parameterizations for modeling soil evaporation. When LST data are not available or when the LST is not considered in the surface energy balance, such formulations can be used together with a canopy conductance model to estimate total the ET. Third, the parameterization that uses the soil moisture content is also used for comparison. In this study, the above-mentioned evaluations are performed at pixel scales, in which case a sound thermal-based two-source energy balance model $\left(\mathrm{TSEB}_{\mathrm{TR}}\right.$ ) is used to determine the "actual" evaporation and transpiration at the pixel scale by using the remotely sensed LST, measured energy fluxes and atmospheric conditions.

\section{Methods}

\subsection{Parameterizations of the soil evaporation}

The soil evaporation is usually estimated by tuning down the potential rate of evaporation ( $\left(\mathrm{LE}_{\mathrm{S} *}\right)$ according to the surface dryness indices, i.e., $\mathrm{LE}_{\mathrm{s} \_ \text {predicted }}=\mathrm{LE}_{\mathrm{S} *} \times$ fun $(\mathrm{SDI})$, in which fun $(\mathrm{SDI})$ is the relative evaporation. First, we introduce three parameterizations of the potential evaporation and then the formulations of the SDI and relative evaporation with respect to the SDI. A summary of all the variables that are used in the soil evaporation parameterizations is shown in Table 1.

The concept of potential ET, which refers to the evapotranspiration rate that would occur for a large uniform surface with an adequate water supply, was first proposed and used by Thornthwaite (1948) for climate classifications. However, as Brutsaert (1982) had indicated, the water/heat feedbacks of the saturated surface to the air are unknown, so the potential rate that is calculated under actual air conditions is not the same as what would occur for a saturated surface. Granger (1989b) noted that the potential rate is indeterminable under the original definition of Thornthwaite

Table 1

Summary of all the variables that are used in the soil evaporation parameterizations.

\begin{tabular}{|c|c|c|}
\hline Variables & & Descriptions/Definitions \\
\hline \multirow{4}{*}{$\begin{array}{l}\text { Potential } \\
\quad \text { evaporation } \\
\text { LE }_{S_{*}}\end{array}$} & $\mathrm{LE}_{\mathrm{s} \_\mathrm{pt}}$ & $\begin{array}{l}\text { Potential } \mathrm{LE}_{\mathrm{s}} \text { estimated using the PT approach } \\
\text { with soil surface available energy, Eq. (1) }\end{array}$ \\
\hline & $\mathrm{LE}_{\mathrm{s} \_\mathrm{pm}}$ & $\begin{array}{l}\text { Potential } \mathrm{LE}_{\mathrm{s}} \text { estimated using the PM approach } \\
\text { with soil surface available energy and the air } \\
\text { humidity, Eq. ( } 2 \text { ) }\end{array}$ \\
\hline & $\mathrm{LE}_{\mathrm{s}_{-} \mathrm{mt}}$ & $\begin{array}{l}\text { Potential } \mathrm{LE}_{\mathrm{s}} \text { estimated using the MT approach } \\
\text { with soil surface temperature and the air } \\
\text { humidity, Eq. ( } 3 \text { ) }\end{array}$ \\
\hline & $\mathrm{LE}_{\mathrm{s} \_\mathrm{air}}$ & $\begin{array}{l}\text { Potential } \mathrm{LE}_{\mathrm{s}} \text { estimated using the MT approach } \\
\text { with air temperature and the air humidity, Eq. } \\
\text { (23) }\end{array}$ \\
\hline \multirow[t]{4}{*}{$\begin{array}{l}\text { Surface dryness } \\
\text { index SDI }\end{array}$} & $\mathrm{SDI}_{1}$ & $\begin{array}{l}\text { Surface dryness index based on } \mathrm{LE}_{\mathrm{s}_{-} \mathrm{mt}} \text { and soil } \\
\text { surface energy balance, Eq. ( } 7 \text { ) }\end{array}$ \\
\hline & $\mathrm{SDI}_{2}$ & $\begin{array}{l}\text { Surface dryness index based on } \mathrm{LE}_{\mathrm{s}_{-} \mathrm{mt}} \text { and relative } \\
\text { humidity of the air, Eq. ( } 8 \text { ) }\end{array}$ \\
\hline & $\mathrm{SDI}_{3}$ & $\begin{array}{l}\text { Surface dryness index based on } \mathrm{LE}_{\mathrm{s} \_ \text {air }} \text { and soil } \\
\text { surface energy balance, Eq. ( } 21)\end{array}$ \\
\hline & $\mathrm{SDI}_{4}$ & $\begin{array}{l}\text { Surface dryness index based on } \mathrm{LE}_{\mathrm{s}_{-} \text {air }} \text { and relative } \\
\text { humidity of the air, Eq. ( } 22 \text { ) }\end{array}$ \\
\hline
\end{tabular}


(1948), but defining useful potential ET indices that represent real and attainable situations is more important.

We applied the potential ET indices that were summarized by Granger (1989b) to the soil layer of a mosaic pixel of the land surface. The first index, which is known as the equilibrium evaporation, refers to the evaporation rate that would occur for a surface that becomes saturated with the energy supply unchanged. The equilibrium evaporation is mainly constrained by the available energy and thus represents a minimal advection situation. The Priestley-Taylor (PT) approach (Priestley and Taylor, 1972) is often used to estimate this potential rate. We apply the PT approach to estimate the equilibrium evaporation for the soil layer $\left(\mathrm{LE}_{\mathrm{s}_{-} \mathrm{pt}}\right)$ of a partially vegetated surface, where $\alpha$ is set to 1.26 :

$L E_{s_{-} p t}=\alpha \frac{\Delta}{\Delta+\gamma}\left(R_{n s}-G\right)$

where $\gamma$ is the psychrometric constant $(0.667 \mathrm{hPa} / \mathrm{K})$ and $\Delta$ is the slope of the saturated vapor pressure to the air temperature. $R_{\mathrm{ns}}$ is the net radiation in the soil layer and $G$ is the soil heat flux.

The second index, which is known as the wet environment evaporation, refers to the evaporation rate that would occur for a surface that becomes saturated with the energy supply and the atmospheric conditions unchanged. This index is usually estimated through the Penman equation (Penman, 1948), which is denoted as $\mathrm{LE}_{\mathrm{s}_{-} \mathrm{pm}}$ :

$L E_{s \_p m}=\frac{\Delta\left(R_{n s}-G\right)+\rho c_{p}\left(e_{*}\left(t_{a}\right)-e_{a}\right) /\left(r_{a}+r_{s}\right)}{\Delta+\gamma}$

where $\rho$ is the air density $\left(1.25 \mathrm{~kg} / \mathrm{m}^{3}\right)$ and $c_{\mathrm{p}}$ is the specific heat of the $\operatorname{air}(1005 \mathrm{~J} / \mathrm{kg} / \mathrm{K})$ at a constant pressure. $e_{\mathrm{a}}$ is the atmospheric water vapor pressure $(\mathrm{hPa})$ and $e_{*}\left(t_{\mathrm{a}}\right)$ is the saturated water vapor pressure of the air at the given air temperature $t_{\mathrm{a}}$. $\mathrm{LE}_{\mathrm{s}_{-} \mathrm{pm}}$ considers the effects of both the available energy and advection on the potential evaporation. Therefore, this function is larger than $\mathrm{LE}_{\mathrm{s} \_\mathrm{pt}}$, and the actual evaporation. $r_{\mathrm{a}}$ and $r_{\mathrm{s}}$ are the aerodynamic and undercanopy resistances in $\mathrm{TSEB}_{\mathrm{TR}}$, respectively, which will be shown in Section 2.2.

The third index refers to the evaporation rate that would occur for a surface that becomes saturated with the current atmospheric conditions and the surface temperature remaining unchanged. This potential evaporation is calculated by the mass transfer equation, which is denoted as $\mathrm{LE}_{\mathrm{s} \_\mathrm{mt}}$. Because no energy limit exists for such cases, $L_{E_{s \_m t}}$ represents the upper limit for the potential evaporation:

$L E_{s_{-} m t}=\frac{\rho c_{p}}{\gamma} \frac{e_{*}\left(T_{s}\right)-e_{a}}{r_{a}+r_{s}}$

where $e_{*}\left(T_{\mathrm{S}}\right)$ is the saturated vapor pressure at the soil surface temperature $T_{s}$.

Surface dryness indices have usually been based on atmospheric humidity data in previous studies to model the ET with minimal data. For example, the surface dryness indices that were proposed by Granger and Gray (1989) and Fisher et al. (2008) are shown in Eqs. (4) and (5), respectively. Granger and Gray (1989) modeled the SDI as a dimensionless index that consists of the available energy at the land surface and the drying power of the air. Higher actual ET and rising soil moisture tends to increase the vapor pressure in the air, thus decreasing the drying power $\left(E_{a}\right.$, Eq. (6)), and vice versa. As a result, the drying power reflects the surface soil moisture content to some extent. Furthermore, Granger and Gray (1989) noted that the sum of the available energy and the drying power represents the upper limit of ET, so the surface dryness index can be formulated as a dimensionless variable, $E_{a} /\left(E_{a}+R_{n}-G\right)$. This index falls into the range of $0-1$. As the land surface becomes saturated, the SDI in Eq. (4) approaches 0 because $E_{a}$ tends to be 0 . On the other hand, if the land surface is completely dry, $\mathrm{E}_{\mathrm{a}}$ reaches its maximum value for the given air conditions, as does the surface dryness index.

$$
\begin{aligned}
& S D I=\frac{E_{a}}{E_{a}+R_{n}-G} \\
& S D I=(R H)^{\left(e_{*}\left(t_{a}\right)-e_{a}\right)} \\
& E_{a}=f(u)\left(e_{*}\left(t_{a}\right)-e_{a}\right)
\end{aligned}
$$

Fisher et al. (2008) also used the air humidity to model the SDI, although their formulation did not consider the surface's available energy (Eq. (5)). The basic logic was also that the air humidity can reflect the surface soil moisture conditions, but, they found that the relative humidity $(\mathrm{RH})$ of the air is lower than the expected relative evaporation at a high vapor pressure deficit (VPD) and higher than the expected relative evaporation at a low VPD, so they modeled $\mathrm{LE}_{\mathrm{s}} / \mathrm{LE}_{\mathrm{s} *}$ as $\mathrm{RH} \mathrm{VPD} / \beta^{\mathrm{V}}$, where $\beta$ is a parameter.

Although the atmospheric humidity is a good indicator of the soil moisture conditions when the surface is in a equilibrium state with the overlying air, such an equilibrium state rarely occurs because of the large-scale advection effect. Instead, the soil surface temperature is strongly influenced by evaporation and can serve as a good indicator of the soil moisture conditions. As a result, we modified the surface dryness indices that were first proposed by Granger and Gray (1989) and Fisher et al. (2008) to incorporate the soil surface temperature. The surface dryness indices are denoted as $\mathrm{SDI}_{1}$ and $\mathrm{SDI}_{2}$, as shown in Eqs. (7) and (8), respectively.

In this study, a constant of 100 in Eq. (8) was used to scale the range of $\mathrm{SDI}_{2}$ to conveniently map the relationship between $\mathrm{SDI}_{2}$ and relative evaporation. This choice does not alter the fitting relationship between $\mathrm{SDI}_{2}$ and the relative evaporation because $\beta$ would change correspondingly if a constant other than 100 was chosen. In addition, Fisher et al. (2008) modeled soil evaporation at monthly scales and used the midday rather than daily mean atmospheric conditions because the link between the surface moisture status and the evaporative demand of the atmosphere is the strongest at midday. Here, we use the near-instantaneous atmospheric measurements to estimate $\mathrm{SDI}_{2}$ because we intend to resolve soil evaporation at sub-daily scales. As with $\mathrm{SDI}_{1}, \mathrm{SDI}_{2}$ can be seen as a function of $\mathrm{LE}_{\mathrm{s}_{-} \mathrm{mt}}$.

$S D I_{1}=\frac{L E_{s \_m t}}{L E_{s \_m t}+R_{n s}-G}$
$S D I_{2}=(R H)^{\left(e_{*}\left(T_{s}\right)-e_{a}\right) / 100}$

The relative evaporation $f$ is calculated as follows:

$f=\frac{L E_{s}}{L E_{s *}}$
$\frac{L E_{s}}{L E_{s *}}=\frac{1}{1+a \exp \left(b \cdot S D I_{1}\right)}$
$\frac{L E_{s}}{L E_{s *}}=S D I_{2}^{\beta}$

Under adequate water supply conditions, the relative evaporation approaches 1 , which indicates that a small coefficient $a$ in Eq. (12) is appropriate. In contrast, when the surface becomes completely dry, $\mathrm{SDI}_{1}$ and the relative evaporation tend to be 1 and 0 , respectively, which indicates that $b$ must be a relatively large number (Eq. (12)). In addition, $a$ is negative when $\mathrm{LE}_{\mathrm{s}} / \mathrm{LE}_{\mathrm{s} \text {-pt }}$ is $>1$. Therefore, the range of $a$ was set to $[-0.5,0.1]$, and the range of $b$ was set to $[0,15]$, for $\mathrm{LE}_{\mathrm{s}} / \mathrm{LE}_{\mathrm{s}_{-} \mathrm{pt}}=\mathrm{fun}\left(\mathrm{SDI}_{1}\right)$. For $\mathrm{LE}_{\mathrm{s}} / \mathrm{LE}_{\mathrm{s}_{\mathrm{p}} \mathrm{pm}}=\mathrm{fun}\left(\mathrm{SDI}_{1}\right)$ and $\mathrm{LE}_{\mathrm{s}} / \mathrm{LE}_{\mathrm{s} \_\mathrm{mt}}=\mathrm{fun}\left(\mathrm{SDI}_{1}\right)$, the range of $a$ was set to $[0,0.1]$ and the range of $b$ was set to $[0,15]$. Similarly, we set the range of $\beta$ to be $[0,10]$.

These three types of potential evaporation indices (Eqs. (1)-(3)) and two types of surface dryness indices (Eqs. (10) and (11)) 
produce six combinations of parameterizations of soil evaporation if the soil surface temperature is available. These combinations can be written in two general forms, which are shown in Eqs. (12) and (13), where $a, b$ and $\beta$ are the aforementioned parameters. Table 2 shows the details of all these combinations.

$L E_{s}=L E_{s *} \cdot \frac{L E_{s}}{L E_{s *}}=L E_{s *} \frac{1}{1+a \exp (b \cdot S D I)}$

$L E_{s}=L E_{s *} \cdot \frac{L E_{s}}{L E_{s *}}=L E_{s *} \cdot S D I^{\beta}$

The two forms of soil evaporation parameterizations that correspond to Eqs. (12) and (13) are shown in Eqs. (14)-(16) and in Eqs. (17)-(19), respectively.

$$
\begin{aligned}
& L E_{s}=L E_{s_{-} p t} \cdot \frac{L E_{s}}{L E_{s_{-} p t}}=L E_{s_{-} p t} \frac{1}{1+a \exp \left(b \cdot S D I_{1}\right)} \\
& L E_{s}=L E_{s_{-} p m} \cdot \frac{L E_{s}}{L E_{s_{-} p m}}=L E_{s_{-} p m} \frac{1}{1+a \exp \left(b \cdot S D I_{1}\right)} \\
& L E_{s}=L E_{s_{-} m t} \cdot \frac{L E_{s}}{L E_{s_{-} m t}}=L E_{s_{-} m t} \frac{1}{1+a \exp \left(b \cdot S D I_{1}\right)} \\
& L E_{s}=L E_{s_{-} p t} \cdot \frac{L E_{s}}{L E_{s_{-} p t}}=L E_{s_{-} p t} \cdot S D I_{2}^{\beta} \\
& L E_{s}=L E_{s_{-} p m} \cdot \frac{L E_{s}}{L E_{s_{-} p m}}=L E_{s_{-} p m} \cdot S D I_{2}^{\beta} \\
& L E_{s}=L E_{s_{-} m t} \cdot \frac{L E_{s}}{L E_{s_{-} m t}}=L E_{s_{-} m t} \cdot S D I_{2}^{\beta}
\end{aligned}
$$

The above equations (Eqs. (14)-(19)) attempt to establish the relationship between the potential evaporation and the actual evaporation directly without using the pixel-scale soil moisture content as input. For example, we can obtain Eq. (20) if we substitute Eq. (7) into Eq. (16). $\mathrm{LE}_{\mathrm{s}}$ is then a function of $\mathrm{LE}_{\mathrm{s} \_\mathrm{mt}}$. In Section 4, we will evaluate the fitness of the parameterizations for actual evaporation data and determine the parameterization with the best performance.

$L E_{s}=L E_{s_{-} m t} \frac{1}{1+a \exp \left(b \cdot \frac{L E_{s \_m t}}{L E_{S_{-} m t}+R_{n s}-G}\right)}$

For conditions in which the soil surface temperature is unavailable, we apply the original formulations of the surface dryness indices that were proposed by Granger and Gray (1989) and Fisher et al. (2008) to the soil layer, as shown in Eqs. (21) and (22), respectively. The ranges of the parameters for $\mathrm{SDI}_{3}$ and $\mathrm{SDI}_{4}$ were the same as for $\mathrm{SDI}_{1}$ and $\mathrm{SDI}_{2}$, respectively.

$\begin{aligned} S D I_{3} & =\frac{L E_{s_{-} a i r}}{L E_{s_{\_} a i r}+R_{n s}-G} \\ S D I_{4} & =(R H)^{\left(e_{*}\left(t_{a}\right)-e_{a}\right) / 100}\end{aligned}$

\begin{tabular}{|c|c|c|c|}
\hline Cases & $\begin{array}{l}\text { Potential evaporation } \\
\text { index } \mathrm{LE}_{\mathrm{S} *}\end{array}$ & $\begin{array}{l}\text { Surface dryness } \\
\text { index SDI }\end{array}$ & $\begin{array}{l}\text { Relationships between } \\
\text { relative evaporation } \\
\text { and SDI }\end{array}$ \\
\hline $\begin{array}{l}1 \\
2 \\
3\end{array}$ & $\begin{array}{l}\mathrm{LE}_{\mathrm{s}_{\_} \mathrm{pt}} \\
\mathrm{LE}_{\mathrm{s}_{-} \mathrm{pm}} \\
\mathrm{LE}_{\mathrm{s}_{\_} \mathrm{mt}}\end{array}$ & $\begin{array}{l}\mathrm{SDI}_{1} \\
\mathrm{SDI}_{1} \\
\mathrm{SDI}_{1}\end{array}$ & $\frac{L E_{s}}{L E_{s *}}=\frac{1}{1+a \exp \left(b \cdot S D I_{1}\right)}$ \\
\hline $\begin{array}{l}4 \\
5 \\
6\end{array}$ & $\begin{array}{l}\mathrm{LE}_{\mathrm{s}_{\mathrm{p}} \mathrm{pt}} \\
\mathrm{LE}_{\mathrm{s}_{\mathrm{p}} \mathrm{pm}} \\
\mathrm{LE}_{\mathrm{s}_{\mathrm{s}} \mathrm{mt}}\end{array}$ & $\begin{array}{l}\mathrm{SDI}_{2} \\
\mathrm{SDI}_{2} \\
\mathrm{SDI}_{2}\end{array}$ & $\frac{L E_{s}}{L E_{s *}}=S D I_{2}^{\beta}$ \\
\hline
\end{tabular}

$\mathrm{LE}_{\mathrm{s} \_ \text {air }}$ is calculated as follows:

$L E_{s_{-} a i r}=\frac{\rho c_{p}}{\gamma} \frac{e_{*}\left(t_{a}\right)-e_{a}}{r_{a}+r_{s}}$

Table 2

Soil evaporation parameterizations that incorporate $T_{\mathrm{s}}$.
Table 3

Soil evaporation parameterizations without $T_{\mathrm{s}}$.

\begin{tabular}{llll}
\hline Cases & $\begin{array}{l}\text { Potential evaporation } \\
\text { index } \mathrm{LE}_{\mathrm{S} *}\end{array}$ & $\begin{array}{l}\text { Surface dryness } \\
\text { index SDI }\end{array}$ & $\begin{array}{l}\text { Relationships between } \\
\text { relative evaporation } \\
\text { and SDI }\end{array}$ \\
\hline 7 & $\mathrm{LE}_{\mathrm{S} \_\mathrm{pt}}$ & $\mathrm{SDI}_{3}$ & $\frac{L E_{s}}{L E_{\mathrm{s}_{*}}}=\frac{1}{1+a \exp \left(b \cdot S D I_{3}\right)}$ \\
8 & $\mathrm{LE}_{\text {S_pm }}$ & $\mathrm{SDI}_{3}$ & \\
9 & $\mathrm{LE}_{\text {S_pt }}$ & $\mathrm{SDI}_{3}$ & $\frac{L E_{\mathrm{s}}}{L E_{\text {s* }}}=\mathrm{SDI}_{4}^{\beta}$ \\
10 & $\mathrm{LE}_{\text {S_pm }}$ & $\mathrm{SDI}_{3}$ & \\
\hline
\end{tabular}

Because the soil surface temperature is unavailable, two potential evaporation indices ( $\mathrm{LE}_{\mathrm{s}_{-} \mathrm{pt}}$ and $\mathrm{LE}_{\mathrm{s} \_\mathrm{pm}}$ ) and two surface dryness indices $\left(\mathrm{SDI}_{3}\right.$ and $\mathrm{SDI}_{4}$ ) provide four parameterization combinations for soil evaporation. These combinations can also be written in two general forms, which are shown in Eqs. (12) and (13). The two forms of soil evaporation parameterizations that correspond to Eqs. (12) and (13) are shown in Eqs. (24) and (25) and in Eqs. (26) and (27), respectively. Table 3 shows the details of all these combinations.

$$
\begin{aligned}
& L E_{s}=L E_{s_{-} p t} \cdot \frac{L E_{s}}{L E_{s_{-} p t}}=L E_{s_{-} p t} \frac{1}{1+a \exp \left(b \cdot S D I_{3}\right)} \\
& L E_{s}=L E_{s_{-} p m} \cdot \frac{L E_{s}}{L E_{s_{-} p m}}=L E_{s_{-} p m} \frac{1}{1+a \exp \left(b \cdot S D I_{3}\right)} \\
& L E_{s}=L E_{s_{-} p t} \cdot \frac{L E_{s}}{L E_{s_{-} p t}}=L E_{s_{-} p t} \cdot S D I_{4}^{\beta} \\
& L E_{s}=L E_{s_{-} p m} \cdot \frac{L E_{s}}{L E_{s_{-} p m}}=L E_{s_{-} p m} \cdot S D I_{4}^{\beta}
\end{aligned}
$$

\subsection{ET partitioning method for evaluating the soil evaporation}

The true values of the near-instantaneous soil evaporation at MODIS pixel scales are required to evaluate the parameterizations that were established in Section 2.1. A detailed review of ET partitioning methods can be found in Kool et al. (2014). In this study, we used the $\mathrm{TSEB}_{\mathrm{TR}}$ model to compute the soil evaporation as a reference to test our soil evaporation parameterizations.

The capability of the TSEB $\mathrm{TR}_{\mathrm{TR}}$ model to estimate ET components has been validated by Colaizzi et al. (2012), who used sap flow data. In addition, the $\mathrm{TSEB}_{\mathrm{TR}}$ model has been used to partition observed LE measurements from an eddy covariance system into transpiration and soil evaporation (Agam et al., 2010). Agam et al. (2010) iteratively ran the TSEB ${ }_{\mathrm{TR}}$ model at each time point with a series of $\alpha$ to achieve minimal error in LE prediction (compared to the LE measurements). Then, the reference LE components that were considered the "true" values were obtained from the minimal error case. We used their method to estimate LE components by using detailed measurements of the atmospheric conditions, the energy fluxes (including soil heat flux), and the land surface temperature.

The calculation procedure is shown in Fig. 1. The net radiation $\left(R_{\mathrm{n}}\right)$ and its partitioning between the canopy $\left(R_{\mathrm{nc}}\right)$ and soil $\left(R_{\mathrm{ns}}\right)$ layers are determined by the atmospheric forcings, the LST and the leaf area index. Then the transpiration $\left(\mathrm{LE}_{\mathrm{c}}\right)$ is estimated for each $\alpha$ through the PT approach, and the sensible heat flux in the canopy layer $\left(H_{c}\right)$ is calculated as the residue of the energy balance equation for the canopy layer. The canopy temperature can then be estimated by inverting the heat transfer equation for $H_{\mathrm{c}}$. The component temperature of the soil layer $\left(T_{\mathrm{s}}\right)$ can be determined by decomposing the LST with the vegetative cover $\left(f_{\mathrm{c}}\right)$ and $T_{\mathrm{c}}$. The sensible heat flux in the soil layer $\left(H_{s}\right)$ can then be calculated by the heat transfer equation, and the latent heat flux in the soil layer $\left(\mathrm{LE}_{\mathrm{S}}\right)$ can be estimated as the residue of the energy balance equation for the soil layer, given that soil heat flux measurements 


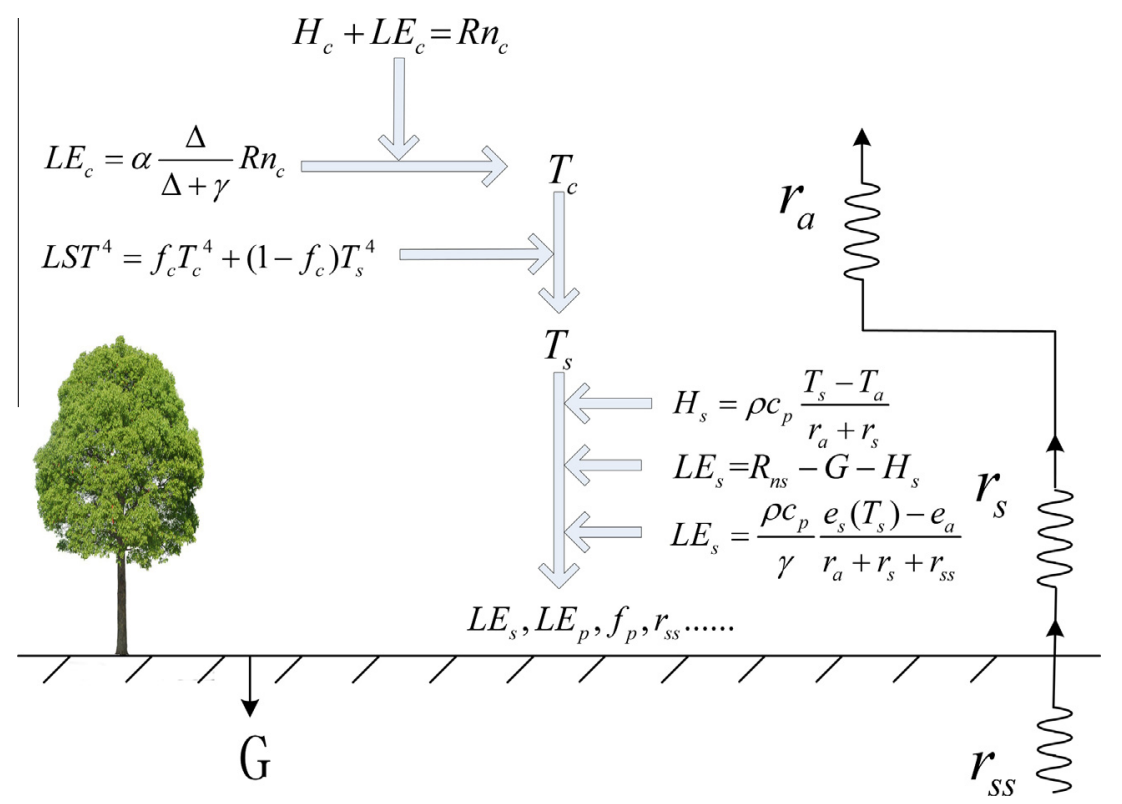

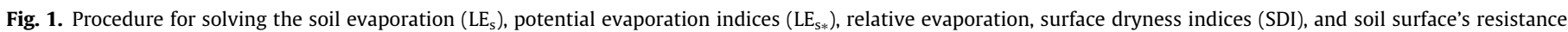
$\left(r_{\mathrm{ss}}\right)$ to water vapor.

are available. The aerodynamic resistance $\left(r_{\mathrm{a}}\right)$ is estimated from the wind speed and the surface roughness (Li et al., 2005). The undercanopy resistance $\left(r_{\mathrm{s}}\right)$ is the resistance to sensible and latent heat fluxes between the soil surface and the canopy displacement height. A detailed description of calculating $r_{\mathrm{s}}$ can be found in Gan and Gao (2015).

At this derivation stage, the soil evaporation $\left(\mathrm{LE}_{\mathrm{s}}\right)$, the potential evaporation indices $\left(\mathrm{LE}_{\mathrm{s}_{\_} \mathrm{pt}}, \mathrm{LE}_{\mathrm{s} \_\mathrm{pm}}\right.$, and $\left.\mathrm{LE}_{\mathrm{S}_{\_} \mathrm{mt}}\right)$, the corresponding relative evaporation, the surface dryness indices $\left(\mathrm{SDI}_{1}, \mathrm{SDI}_{2}, \mathrm{SDI}_{3}\right.$ and $\left.\mathrm{SDI}_{4}\right)$ and the soil surface resistance $\left(r_{\mathrm{ss}}\right)$ to water vapor can be estimated. The soil evaporation from the optimized TSEB $_{\mathrm{TR}}$ is considered as the reference $L E_{s}$, which is used as the approximation of the actual evaporation. We then use the reference LEs to evaluate each parameterization that was established in Section 2.1 to estimate the soil evaporation.

\section{Study sites and data description}

We evaluated the soil evaporation parameterizations at two crop sites, i.e., the Daxing site and Tongyu site, which are located in semi-humid and semi-arid areas in China, respectively. Assessing and improving agricultural water use efficiency are important for water resource sustainability in these areas. In-situ measurements from the Daxing site were provided by the Cold and Arid Regions Science Data Center at Lanzhou (http://westdc.westgis. ac.cn/haihe/daxing) (Liu and Xu, 2013), and the data from the Tongyu site were obtained from the Coordinated Energy and Water Cycle Observations Project's (CEOP) reference site data archive (http://www.ceop.net/).

The Daxing site $\left(39.6123^{\circ} \mathrm{N}, 116.4270^{\circ} \mathrm{E}\right)$ is located in a cropland with very flat terrain (Jia et al., 2012; Liu et al., 2013) in the Hai River Basin in the northern plain of China. The mean annual precipitation in the Hai River Basin (1956-2000) is $527 \mathrm{~mm}$, which only constitutes $1.5 \%$ of the national total water resources but supplies water to $10 \%$ of the population of the country (Liu et al., 2013; Sun, 2013). Winter wheat, maize, and vegetables are planted at this crop site, with maximum heights of $0.7 \mathrm{~m}, 2.2 \mathrm{~m}$, and $0.5 \mathrm{~m}$, respectively (Liu et al., 2013).
The Tongyu site is located on the SongNen plain, which is the second largest plain and one of the most important areas of grain production in China. The SongNen plain, which is located in northeastern China, is characterized by a temperate, semi-arid continental monsoon climate (Yu et al., 2014). The sustainable development of agriculture in this area has long been restricted because of drought and water shortage (Wang et al., 2003). The annual mean air temperature at the Tongyu site is $5.2{ }^{\circ} \mathrm{C}$, and the annual mean precipitation is $404.3 \mathrm{~mm}$. Corn is planted at this crop site $\left(44.5921^{\circ} \mathrm{N}, 122.8773^{\circ} \mathrm{E}\right)$ and reaches its maximum height ( 1.8 m) in September (Tu, 2007).

All the data that were used in this study are summarized in Table 4. The land surface temperature, albedo, and leaf area index data at the study sites were obtained from the MODIS products, which were downloaded from the Goddard Space Flight Center (http://ladsweb.nascom.nasa.gov/data/). The data sets that were used to evaluate the soil evaporation parameterizations were collected when the highest quality MOD11L2/MYD11L2 LST data were available, i.e., the quality control (qc) flags equaled 0 , during the study periods (2009 at the Daxing site, and 2003 and 2004 at the Tongyu site). These data sets include remotely sensed products, atmospheric forcing, and soil moisture and energy flux measurements.

All the in-situ measurements at both sites were recorded at an interval of $30 \mathrm{~min}$, except for the atmospheric and sub-surface measurements at the Daxing site, which were recorded every $10 \mathrm{~min}$. However, these data were averaged to match the $30-\mathrm{min}$ scale.

The EC systems measured fluxes at the spatial scale of the MODIS LST (approximately $0.01^{\circ}$ ) because the stations were surrounded by homogeneous flat terrain and were not sheltered by tall obstacles. Closure corrections were performed on the sensible and latent heat fluxes from the EC systems before the flux measurements could be used. We partitioned the available energy $\left(R_{\mathrm{n}}-\right.$ $-G$ ) between the sensible and latent heat fluxes by using the 30min average evaporative fraction $\mathrm{LE} /(\mathrm{H}+\mathrm{LE})$ that was calculated from the EC measurements (Twine et al., 2000).

Soil heat flux measurements below the surface usually do not equal the corresponding surface values. At the Tongyu site, we used the calorimetric method (Heusinkveld et al., 2004) to esti- 
Table 4

Summary of the data that were used in this study.

\begin{tabular}{|c|c|c|c|c|}
\hline \multirow[t]{2}{*}{ Data } & \multirow[t]{2}{*}{ Measurements } & \multicolumn{2}{|c|}{ Height/m } & \multirow[t]{2}{*}{ Usage } \\
\hline & & Tongyu & Daxing & \\
\hline Forcings & $\begin{array}{l}\text { Incoming radiation } \\
\text { Air temperature } \\
\text { Specific humidity } \\
\text { Air pressure } \\
\text { Wind speed }\end{array}$ & $\begin{array}{l}3 \\
3.95 \\
3.95 \\
1.5 \\
17.06\end{array}$ & $\begin{array}{l}28 \\
10 \\
27 \\
27 \\
27\end{array}$ & $\begin{array}{l}R_{\mathrm{s}} \downarrow, R_{\mathrm{l}} \downarrow^{\mathrm{a}} \\
T_{\mathrm{a}} \\
\text { Estimate } e_{\mathrm{a}} \\
\mathrm{P}_{\mathrm{a}} \\
u\end{array}$ \\
\hline Subsurface measurements & $\begin{array}{l}\text { Soil temperature } \\
\text { Soil moisture }\end{array}$ & $\begin{array}{l}-0.02 \\
-0.05\end{array}$ & $\begin{array}{l}-0.02 \\
-0.02\end{array}$ & $\begin{array}{l}\text { Estimate } G \\
\text { swc }\end{array}$ \\
\hline Flux measurements & $\begin{array}{l}\text { Sensible heat fluxes } \\
\text { Latent heat fluxes } \\
\text { Soil heat flux }\end{array}$ & $\begin{array}{l}3.5 \\
3.5 \\
-0.05\end{array}$ & $\begin{array}{l}3 \\
3 \\
-0.02\end{array}$ & $\begin{array}{l}H \\
\text { LE } \\
\text { Estimate } G\end{array}$ \\
\hline MODIS products & $\begin{array}{l}\text { MOD11L2/MYD11L2 } \\
\text { MOD15A2 } \\
\text { MCD43B3 }\end{array}$ & $\begin{array}{l}- \\
- \\
-\end{array}$ & $\begin{array}{l}- \\
- \\
-\end{array}$ & $\begin{array}{l}\text { LST } \\
\text { LAI } \\
\text { albedo }\end{array}$ \\
\hline
\end{tabular}

${ }^{\text {a }} R_{\mathrm{s}} \downarrow$ and $R_{\mathrm{l}} \downarrow$ are the incoming shortwave and longwave radiation, respectively.

mate the soil heat flux at the surface by combining the heat storage in the top $0.05-\mathrm{m}$ soil layer and the soil heat flux at $0.05 \mathrm{~m}$ below the surface. However, both the soil heat flux and the soil temperature at the Daxing site were measured at a depth of $0.02 \mathrm{~m}$, so we used the original measurements of the soil heat flux as a surrogate of the surface values.

\section{Results and discussion}

\section{1. $T S E B_{T R}$ model performances}

We iteratively ran the TSEB ${ }_{\mathrm{TR}}$ model at the timings in which the MODIS LST data with the highest quality were available to obtain the total LE and its partitioning between the canopy and soil layers. In addition, we calculated a series of potential evaporation indices by using the PT approach, the Penman approach, and the mass transfer method, for all the timings ( $q \mathrm{c}=0$ for LST) of the study periods. The drying power of the air, $\mathrm{LE}_{\mathrm{s} \_ \text {air }}$, was also determined by using the mass transfer equation with the atmospheric water vapor deficit. Table 5 shows the minimum, maximum and mean values of all the above-mentioned variables and the EC measurements. The relative evaporation and the surface dryness indices $\left(\mathrm{SDI}_{1}, \mathrm{SDI}_{2}, \mathrm{SDI}_{3}\right.$, and $\mathrm{SDI}_{4}$ ) could also be determined.

Soil evaporation comprised a considerable fraction of the total ET, i.e., 53.4\% and 34.0\%, at the Daxing and Tongyu sites, respectively (Table 5). Time series of the LAI and the soil moisture content are shown in Figs. 2-4. The timings of the data at the Tongyu site mainly lay in the growing periods of the crop, which indicates that the fraction of soil evaporation in the total ET would have been $>34.0 \%$ at an annual scale. An urgent need exists to study soil evaporation parameterization.

Table 5

Ranges of the predicted LE values, the LE components and the potential evaporation indexes at both sites. $\mathrm{LE}_{-\mathrm{EC}}$ represents the EC measurements.

\begin{tabular}{|c|c|c|c|c|c|c|}
\hline & \multicolumn{3}{|l|}{ Daxing } & \multicolumn{3}{|l|}{ Tongyu } \\
\hline & $\begin{array}{l}\text { Min } \\
\left(\mathrm{W} / \mathrm{m}^{2}\right)\end{array}$ & Max & Mean & $\begin{array}{l}\text { Min } \\
\left(\mathrm{W} / \mathrm{m}^{2}\right)\end{array}$ & Max & Mean \\
\hline $\mathrm{LE}_{-\mathrm{EC}}$ & 18.4 & 521.9 & 251.8 & 39.4 & 496.6 & 213.5 \\
\hline $\mathrm{LE}$ & 10.6 & 525.0 & 253.7 & 49.0 & 493.2 & 223.4 \\
\hline $\mathrm{LE}_{\mathrm{c}}$ & 2.7 & 327.6 & 118.1 & 18.1 & 396.1 & 147.4 \\
\hline $\mathrm{LE}_{\mathrm{s}}$ & 0.5 & 353.8 & 135.6 & 4.0 & 202.2 & 76.0 \\
\hline $\mathrm{LE}_{\mathrm{s}_{-} \mathrm{pt}}$ & 34.9 & 341.2 & 203.3 & 75.0 & 312.4 & 192.6 \\
\hline $\mathrm{LE}_{\mathrm{s} \_\mathrm{pm}}$ & 73.8 & 465.7 & 286.0 & 95.8 & 503.1 & 255.7 \\
\hline $\mathrm{LE}_{\mathrm{s} \_\mathrm{mt}}$ & 101.1 & 1758.9 & 745.4 & 125.3 & 2581.8 & 930.5 \\
\hline $\mathrm{LE}_{\mathrm{S} \_ \text {air }}$ & 76.1 & 1085.1 & 460.9 & 91.8 & 1563.5 & 406.2 \\
\hline
\end{tabular}

Table 5 shows that the total LE that was predicted by the optimized TSEB $_{\mathrm{TR}}$ model matched the EC measurements well, with similar ranges and mean values. In addition, the RMSE and mean bias in the total LE at the Daxing site were $25.7 \mathrm{~W} / \mathrm{m}^{2}$ and $1.9 \mathrm{~W} /$ $\mathrm{m}^{2}$, respectively, whereas the RMSE and mean bias in the total LE at the Tongyu site were $36.1 \mathrm{~W} / \mathrm{m}^{2}$ and $18.1 \mathrm{~W} / \mathrm{m}^{2}$, respectively (Table 6). The mean LE that was measured by the EC system (LE_EC) was $251.8 \mathrm{~W} / \mathrm{m}^{2}$ and $213.5 \mathrm{~W} / \mathrm{m}^{2}$ at the Daxing and Tongyu sites, respectively (Table 6). Therefore, the ratios of the RMSEs to the mean EC measurements, which are called "relative RMSEs" in the rest of the paper, were quite small, which indicate the capability of the optimized $\mathrm{TSEB}_{\mathrm{TR}}$ model to reproduce the energy fluxes.

We compared the performances of the model that used the qualified LST data $(\mathrm{qc}=0)$ and the un-qualified LST data $(\mathrm{qc}>0)$ over the entire study periods to further evaluate the capability of the optimized $\mathrm{TSEB}_{\mathrm{TR}}$ model. At the Daxing site, the fraction of LST data that were qualified was relatively high (78\%), and the relative RMSEs were only $8.1 \%$ and $11.0 \%$ for the timings when qc $>0$ and $\mathrm{qc}=0$, respectively (Table 6 ). In contrast, the fraction of LST data at the Tongyu site that were qualified was only $48.7 \%$. In addition, the relative RMSE for the model that used the unqualified LST data (32.9\%) was much higher than that for the model that used the qualified LST data (12.9\%) (Table 6). Thus, we only selected the timings when the qualified LST data were available.

Figs. 2-4 show that the optimized TSEB $_{\mathrm{TR}}$ model that used quality-controlled LST data reproduced the LE values throughout the range of fractional vegetation cover at both sites. These good performances, especially during periods with low vegetation cover, during which the effects of adjusting $\alpha$ were quite minor, indicated that the parameterizations of net radiation partitioning and the resistance terms of heat transfer in $\mathrm{TSEB}_{\mathrm{TR}}$ were reasonable. Therefore, LE partitioning is assumed to be reasonable after iteratively running the $\mathrm{TSEB}_{\mathrm{TR}}$ model with both flux measurements and the land surface temperature serving as constraints to force closure on the LE partitioning.

\subsection{Evaluating the soil evaporation parameterizations that incorporated the LST}

In this section, we establish and evaluate the relationships between the relative evaporation and the surface dryness indices $\left(\mathrm{SDI}_{1}\right.$ and $\left.\mathrm{SDI}_{2}\right)$ that incorporate LST and determine how well the soil evaporation parameterizations (Eqs. (14)-(19)) that are based on the potential evaporation and relative evaporation concepts can fit the observation data. The fitted curve between $\mathrm{LE}_{\mathrm{s}} / \mathrm{LE}_{\mathrm{S}_{\mathrm{B}} \mathrm{pt}}$ and 

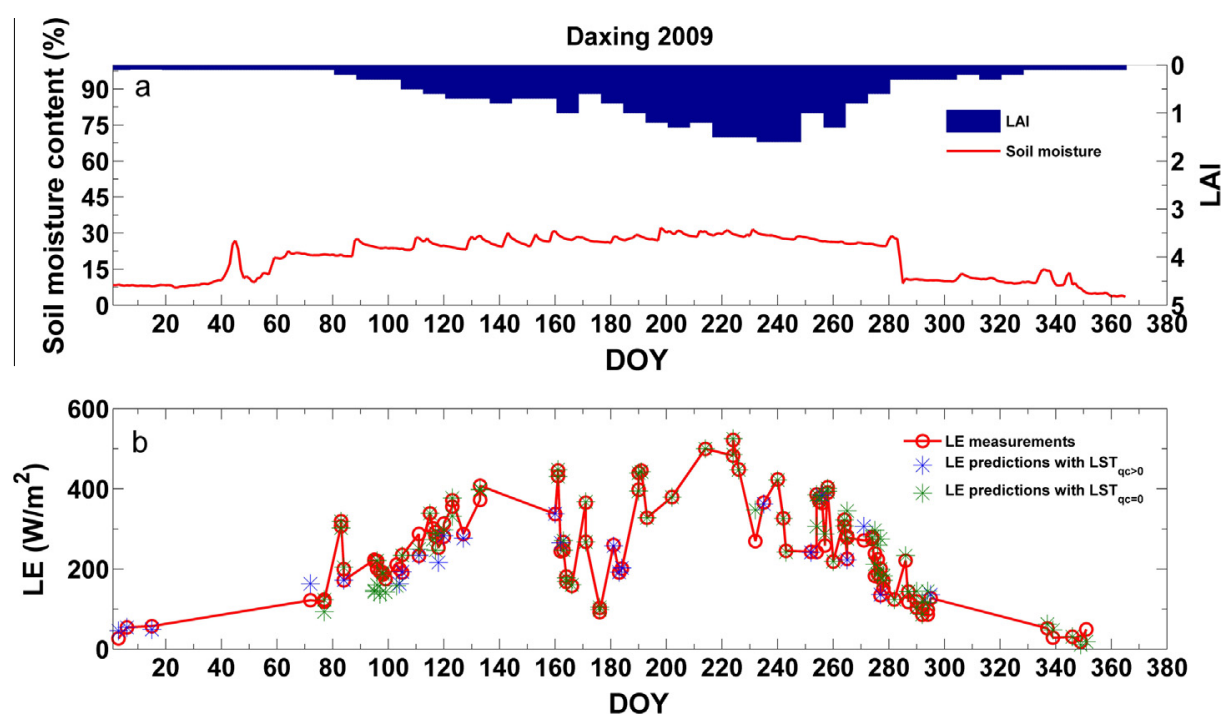

Fig. 2. Time series of the soil moisture content, LAI, latent heat flux predictions and EC measurements at the Daxing site in 2009.
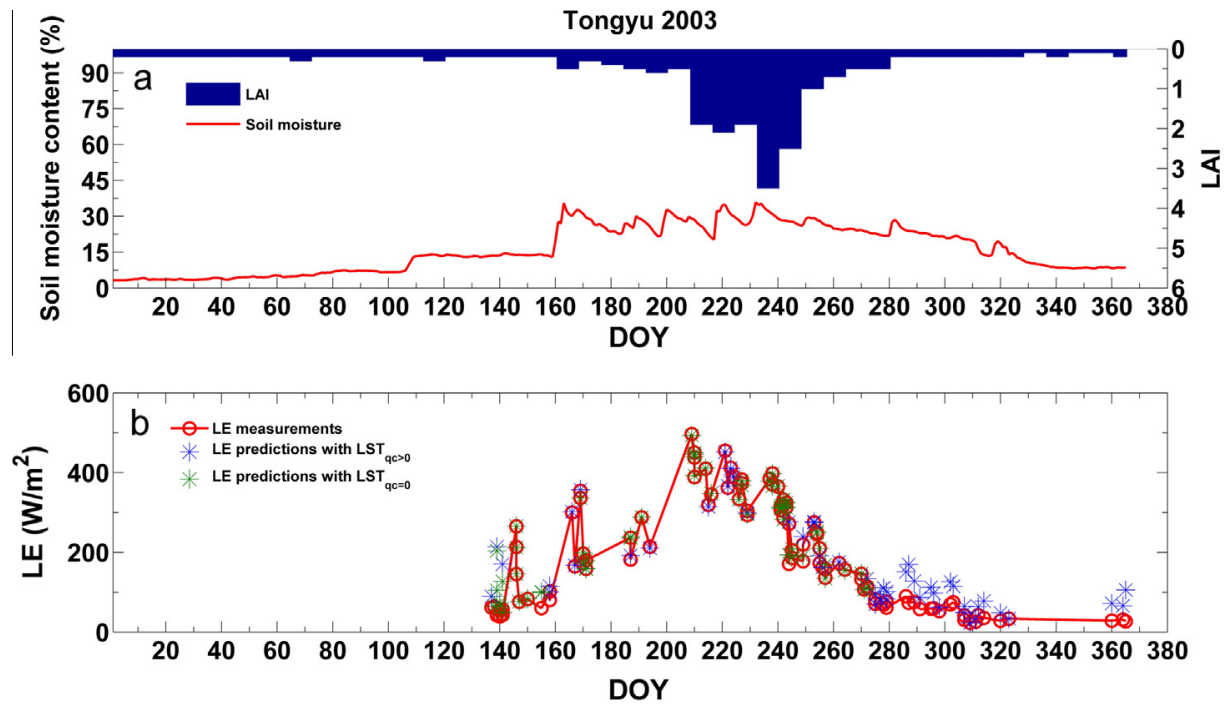

Fig. 3. Time series of the soil moisture content, LAI, latent heat flux predictions and EC measurements at the Tongyu site in 2003.

$\mathrm{SDI}_{1}$ was denoted as $\mathrm{LE}_{\mathrm{s}} / \mathrm{LE}_{\mathrm{s} \text { pt }}=\mathrm{fun}\left(\mathrm{SDI}_{1}\right)$. Similar notations are used in the rest of this study.

The simulated annealing technique (Dekkers and Aarts, 1991; Kirkpatrick et al., 1983) was used to estimate the parameters in the relationships between the relative evaporation and SDI. The simulated annealing technique can achieve global optima by socalled hill-climbing moves to avoid being trapped in local minima. The estimated parameters, RMSEs and biases of the predicted relative evaporation values are shown in Table 7 . For $\mathrm{SDI}_{1}$, the results at both sites indicated that $\mathrm{LE}_{\mathrm{s}} / \mathrm{LE}_{\mathrm{s}_{-} \mathrm{mt}}=\mathrm{fun}\left(\mathrm{SDI}_{1}\right)$ performed the best, followed by $\mathrm{LE}_{\mathrm{s}} / \mathrm{LE}_{\mathrm{s}_{\mathrm{B}} \mathrm{pm}}=$ fun $\left(\mathrm{SDI}_{1}\right)$, whereas $\mathrm{LE}_{\mathrm{s}} / \mathrm{LE}_{\mathrm{s} \_\mathrm{pt}}=$ fun $\left(\mathrm{SDI}_{1}\right)$ performed the worst. Similar results were found for $\mathrm{SDI}_{2}$.

In addition, $\mathrm{SDI}_{1}$ was generally better than $\mathrm{SDI}_{2}$ for modeling the same $\mathrm{LE}_{\mathrm{s}} / \mathrm{LE}_{\mathrm{s} *}$ at the same site for most cases, except for the bias in $\mathrm{LE}_{\mathrm{s}} / \mathrm{LE}_{\mathrm{s} \_\mathrm{pt}}=$ fun $\left(\mathrm{SDI}_{1}\right)$ at the Daxing site, which was much larger than those in the other cases (Table 7). Both surface dryness indices $\mathrm{SDI}_{1}$ and $\mathrm{SDI}_{2}$ include the factor $e_{*}\left(T_{\mathrm{s}}\right)-e_{\mathrm{a}}$ to indicate the water availability of the surface. However, the soil temperature itself is the result of the surface energy balance and can change if the available energy changes under the same water supply conditions. This indicates that no one-to-one matching relationship exists between the soil temperature and the soil water availability. Compared to $\mathrm{SDI}_{2}, \mathrm{SDI}_{1}$ is a normalized factor that considers both the soil temperature and the energy balance effect of the surface when indicating the surface dryness.

We also examined whether $\mathrm{LE}_{\mathrm{s}}$ can be expressed as a function of a potential evaporation index and a surface dryness index (Eqs. (14)-(19)). Such functions can be denoted as, e.g., $\mathrm{LE}_{\mathrm{s}}=\mathrm{Fun}\left(\mathrm{LE}_{\mathrm{s} \_\mathrm{mt}}\right.$, $\mathrm{SDI}_{1}$ ) for Eq. (14). Similar notations are used in the rest of the paper. Although $\mathrm{LE}_{\mathrm{s}} / \mathrm{LE}_{\mathrm{s}_{\_} \mathrm{mt}}$ can be modeled quite well with both surface dryness indices $\mathrm{SDI}_{1}$ and $\mathrm{SDI}_{2}$, the accuracy of reproducing the evaporation by using $\mathrm{LE}_{\mathrm{s} \_\mathrm{mt}}$ as the potential evaporation index may be unsatisfactory (Tables 7 and 8, Figs. 5 and 6). For example, the case $\mathrm{LE}_{\mathrm{s}}=\mathrm{Fun}\left(\mathrm{LE}_{\mathrm{s} \_\mathrm{mt}}, \mathrm{SDI}_{2}\right)$ performed the worst at both sites compared to the other parameterizations. The main reason was that $\mathrm{LE}_{\mathrm{s}_{-} \mathrm{mt}}$ was much larger than the other potential evaporation indices (Table 5), which means that relatively small errors in $\mathrm{LE}_{\mathrm{s}} /$ $\mathrm{LE}_{\mathrm{S} \_\mathrm{mt}}$ could induce large errors in the predicted $\mathrm{LE}_{\mathrm{s}}$. Although the $\mathrm{LE}_{\mathrm{s}}$ estimation was found to be quite accurate at both sites for $L_{E_{\mathrm{s}}}=\mathrm{Fun}\left(\mathrm{LE}_{\mathrm{s} \_\mathrm{mt}}, \mathrm{SDI}_{1}\right)$, where the RMSEs for $\mathrm{LE}_{\mathrm{s}} / \mathrm{LE}_{\mathrm{s}_{-} \mathrm{mt}}=$ fun $\left(\mathrm{SDI}_{1}\right)$ were the lowest, our results indicated that $\mathrm{LE}_{\mathrm{s} \_\mathrm{mt}}$ was not a robust potential evaporation index to estimate the soil 

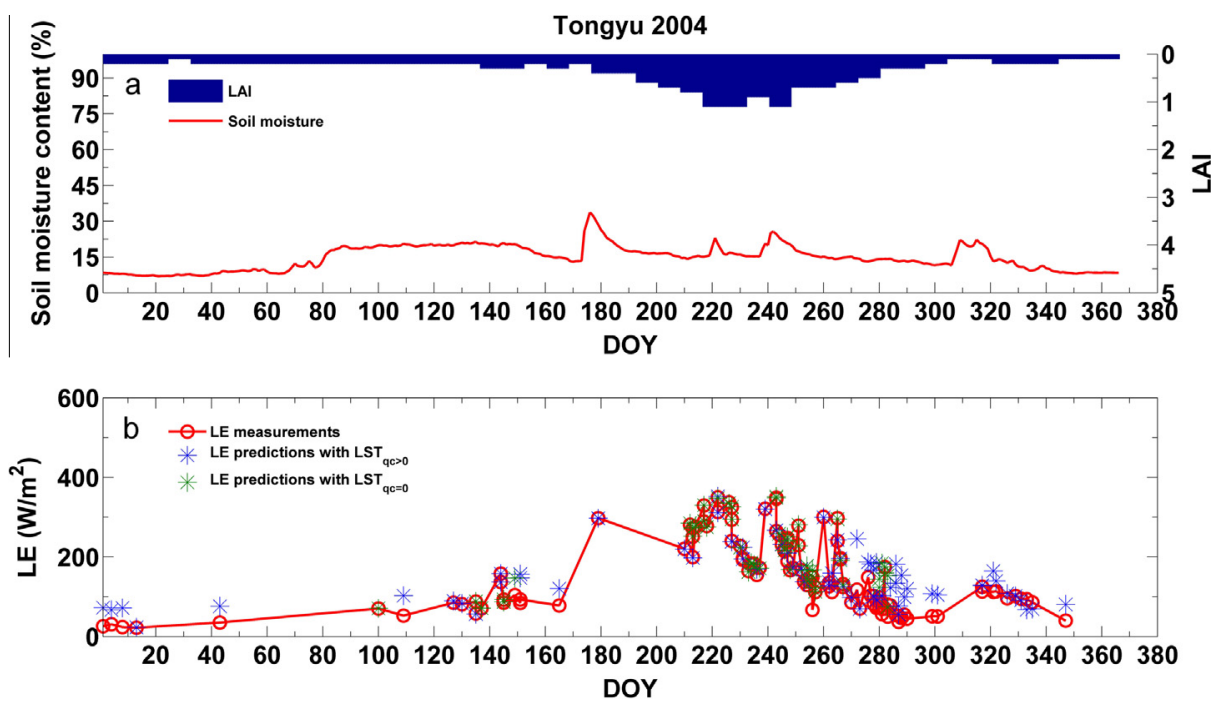

Fig. 4. Time series of the soil moisture content, LAI, latent heat flux predictions and EC measurements at the Tongyu site in 2004.

Table 6

Statistical results of the TSEB $\mathrm{TR}_{\mathrm{TR}}$ model performances at both sites.

\begin{tabular}{llllll}
\hline \multirow{2}{*}{ Daxing } & Count & $\begin{array}{l}\text { RMSE } \\
\left(\mathrm{W} / \mathrm{m}^{2}\right)\end{array}$ & $\begin{array}{l}\text { Bias } \\
\left(\mathrm{W} / \mathrm{m}^{2}\right)\end{array}$ & $\begin{array}{l}\text { Mean LE} \\
\left(\mathrm{W} / \mathrm{m}^{2}\right)\end{array}$ \\
& $\mathrm{LST}_{\mathrm{qc}>0}$ & 24 & 17.2 & 2.1 & 213.4 \\
\multirow{3}{*}{ Tongyu } & $\mathrm{LST}_{\mathrm{qc}=0}$ & 85 & 27.6 & 1.9 & 251.8 \\
& $\mathrm{LST}_{\mathrm{qc}>0}$ & 117 & 42.6 & 25.7 & 129.3 \\
& $\mathrm{LST}_{\mathrm{qc}=0}$ & 111 & 27.6 & 9.9 & 213.5 \\
\hline
\end{tabular}

Table 7

Fitting results of the relative evaporation curves.

\begin{tabular}{|c|c|c|c|c|c|}
\hline & $\begin{array}{l}\text { Relative evaporation } \\
\text { parameterizations }\end{array}$ & $a$ & $b$ & RMSE & BIAS \\
\hline Daxing & $\begin{array}{l}\mathrm{LE}_{\mathrm{s}} / \mathrm{LE}_{\mathrm{s} \_\mathrm{pt}}=\text { fun }\left(\mathrm{SDI}_{1}\right) \\
\mathrm{LE}_{\mathrm{s}} / \mathrm{LE}_{\mathrm{s} \_\mathrm{pm}}=\text { fun }\left(\mathrm{SDI}_{1}\right) \\
\mathrm{LE}_{\mathrm{s}} / \mathrm{LE}_{\mathrm{s} \_\mathrm{mt}}=\text { fun }\left(\mathrm{SDI}_{1}\right)\end{array}$ & $\begin{array}{l}0.03539 \\
0.00021 \\
0.00182\end{array}$ & $\begin{array}{l}4.22 \\
11.59 \\
10.32\end{array}$ & $\begin{array}{l}0.259 \\
0.170 \\
0.102\end{array}$ & $\begin{array}{l}-0.076 \\
0.007 \\
0.006\end{array}$ \\
\hline Tongyu & $\begin{array}{l}\mathrm{LE}_{\mathrm{s}} / \mathrm{LE}_{\mathrm{s} \_\mathrm{pt}}=\text { fun }\left(\mathrm{SDI}_{1}\right) \\
\mathrm{LE}_{\mathrm{s}} / \mathrm{LE}_{\mathrm{s} \_\mathrm{pm}}=\text { fun }\left(\mathrm{SDI}_{1}\right) \\
\mathrm{LE}_{\mathrm{s}} / \mathrm{LE}_{\mathrm{s} \_\mathrm{mt}}=\text { fun }\left(\mathrm{SDI}_{1}\right)\end{array}$ & $\begin{array}{l}0.00059 \\
1.65 e-5 \\
0.00029\end{array}$ & $\begin{array}{l}9.81 \\
14.92 \\
13.01\end{array}$ & $\begin{array}{l}0.128 \\
0.082 \\
0.038\end{array}$ & $\begin{array}{l}0.004 \\
-0.006 \\
0.003\end{array}$ \\
\hline & $\begin{array}{l}\text { Relative evaporation } \\
\text { parameterizations }\end{array}$ & $\beta$ & & RMSE & BIAS \\
\hline Daxing & $\begin{array}{l}\mathrm{LE}_{\mathrm{s}} / \mathrm{LE}_{\mathrm{s} \_\mathrm{pt}}=\text { fun }\left(\mathrm{SDI}_{2}\right) \\
\mathrm{LE}_{\mathrm{s}} / \mathrm{LE}_{\mathrm{s} \_\mathrm{pm}}=\text { fun }\left(\mathrm{SDI}_{2}\right) \\
\mathrm{LE}_{\mathrm{s}} / \mathrm{LE}_{\mathrm{s}_{-} \mathrm{mt}}=\text { fun }\left(\mathrm{SDI}_{2}\right)\end{array}$ & $\begin{array}{l}0.264 \\
1.739 \\
3.942\end{array}$ & & $\begin{array}{l}0.264 \\
0.248 \\
0.190\end{array}$ & $\begin{array}{l}0.006 \\
0.006 \\
-0.006\end{array}$ \\
\hline Tongyu & $\begin{array}{l}\mathrm{LE}_{\mathrm{s}} / \mathrm{LE}_{\mathrm{s} \_\mathrm{pt}}=\text { fun }\left(\mathrm{SDI}_{2}\right) \\
\mathrm{LE}_{\mathrm{s}} / \mathrm{LE}_{\mathrm{s} \_\mathrm{pm}}=\text { fun }\left(\mathrm{SDI}_{2}\right) \\
\mathrm{LE}_{\mathrm{s}} / \mathrm{LE}_{\mathrm{s} \_\mathrm{mt}}=\text { fun }\left(\mathrm{SDI}_{2}\right)\end{array}$ & $\begin{array}{l}1.764 \\
2.300 \\
5.600\end{array}$ & & $\begin{array}{l}0.177 \\
0.150 \\
0.100\end{array}$ & $\begin{array}{l}0.001 \\
-0.003 \\
-0.018\end{array}$ \\
\hline
\end{tabular}

evaporation estimation. However, if $\mathrm{LE}_{\mathrm{s} \_\mathrm{mt}}$ is used, the surface dryness index $\mathrm{SDI}_{1}$ is suggested.

When $\mathrm{LE}_{\mathrm{s} \_\mathrm{pt}}$ was used as the potential evaporation index, the $L_{s}$ estimation was generally reasonable, except for $L_{s}=$ Fun $\left(\mathrm{LE}_{\mathrm{s} \_\mathrm{pt}}, \mathrm{SDI}_{1}\right)$, which resulted in a relatively large bias $(-20.7 \mathrm{~W} /$ $\mathrm{m}^{2}$ ) at the Daxing site. The major advantage of $\mathrm{LE}_{\mathrm{s} \text { pt }}$ is that this factor requires minimal data as input, compared to other potential evaporation indices. In contrast, both $\mathrm{LE}_{\mathrm{s}}=\mathrm{Fun}\left(\mathrm{LE}_{\mathrm{s}_{-} \mathrm{pm}}, \mathrm{SDI}_{1}\right)$ and $\mathrm{LE}_{\mathrm{S}}=\mathrm{Fun}\left(\mathrm{LE}_{\mathrm{s} \_\mathrm{pm}}, \mathrm{SDI}_{2}\right)$ performed quite well, which suggests that LEs_pm is a robust potential evaporation index for soil evaporation estimation. The relative RMSEs in $\mathrm{LE}_{\mathrm{s}}$ for $\mathrm{LE}_{\mathrm{s}}=\mathrm{Fun}\left(\mathrm{LE}_{\mathrm{s} \_\mathrm{pm}}, \mathrm{SDI}_{1}\right)$ were relatively low, i.e., $29.9 \%$ and $28.0 \%$ at the Daxing and Tongyu sites, respectively.
Table 8

RMSEs and biases of $\mathrm{LE}_{\mathrm{s}}$ from different parameterizations that incorporated the soil temperature in the potential evaporation indexes or the surface dryness indexes.

\begin{tabular}{|c|c|c|c|}
\hline & $\mathrm{LE}_{\mathrm{s}}$ parameterizations & $\operatorname{RMSE}\left(\mathrm{W} / \mathrm{m}^{2}\right)$ & BIAS $\left(\mathrm{W} / \mathrm{m}^{2}\right)$ \\
\hline \multirow[t]{3}{*}{ Daxing } & $\mathrm{LE}_{\mathrm{s}}=\mathrm{Fun}\left(\mathrm{LE}_{\mathrm{s}-\mathrm{pt}}, \mathrm{SDI}_{1}\right)$ & 55.6 & -20.7 \\
\hline & $\mathrm{LE}_{\mathrm{s}}=\operatorname{Fun}\left(\mathrm{LE}_{\mathrm{s}-\mathrm{pm}}, \mathrm{SDI}_{1}\right)$ & 40.6 & -4.6 \\
\hline & $\mathrm{LE}_{\mathrm{s}}=\operatorname{Fun}\left(\mathrm{LE}_{\mathrm{s} \_\mathrm{mt}}, \mathrm{SDI}_{1}\right)$ & 51.0 & 3.1 \\
\hline \multirow[t]{4}{*}{ Tongyu } & $\mathrm{LE}_{\mathrm{s}}=\mathrm{Fun}\left(\mathrm{LE}_{\mathrm{s} \_\mathrm{pt}}, \mathrm{SDI}_{1}\right)$ & 25.3 & 3.3 \\
\hline & $\mathrm{LE}_{\mathrm{s}}=\operatorname{Fun}\left(\mathrm{LE}_{\mathrm{s}-\mathrm{pm}}, \mathrm{SDI}_{1}\right)$ & 21.3 & -0.1 \\
\hline & $\mathrm{LE}_{\mathrm{s}}=\operatorname{Fun}\left(\mathrm{LE}_{\mathrm{s} \_\mathrm{mt}}, \mathrm{SDI}_{1}\right)$ & 29.0 & 8.4 \\
\hline & $\mathrm{LE}_{\mathrm{s}}$ parameterizations & $\operatorname{RMSE}\left(\mathrm{W} / \mathrm{m}^{2}\right)$ & $\operatorname{BIAS}\left(\mathrm{W} / \mathrm{m}^{2}\right)$ \\
\hline \multirow[t]{3}{*}{ Daxing } & $\mathrm{LE}_{\mathrm{s}}=\mathrm{Fun}\left(\mathrm{LE}_{\mathrm{s}-\mathrm{pt}}, \mathrm{SDI}_{2}\right)$ & 51.2 & -6.7 \\
\hline & $\mathrm{LE}_{\mathrm{s}}=\mathrm{Fun}\left(\mathrm{LE}_{\mathrm{s}_{-} \mathrm{pm}}, \mathrm{SDI}_{2}\right)$ & 60.7 & -7.2 \\
\hline & $\mathrm{LE}_{\mathrm{s}}=\operatorname{Fun}\left(\mathrm{LE}_{\mathrm{s} \_\mathrm{mt}}, \mathrm{SDI}_{2}\right)$ & 89.9 & -15.0 \\
\hline \multirow[t]{3}{*}{ Tongyu } & $\mathrm{LE}_{\mathrm{s}}=\mathrm{Fun}\left(\mathrm{LE}_{\mathrm{s}-\mathrm{pt}}, \mathrm{SDI}_{2}\right)$ & 34.0 & 1.5 \\
\hline & $\mathrm{LE}_{\mathrm{s}}=\operatorname{Fun}\left(\mathrm{LE}_{\mathrm{s}_{-} \mathrm{pm}}, \mathrm{SDI}_{2}\right)$ & 37.9 & 1.2 \\
\hline & $\mathrm{LE}_{\mathrm{s}}=\operatorname{Fun}\left(\mathrm{LE}_{\mathrm{s} \_\mathrm{mt}}, \mathrm{SDI}_{2}\right)$ & 70.4 & -9.9 \\
\hline
\end{tabular}

Incorporating the soil temperature into the estimation of soil evaporation and evaluating such parameterizations with a thermal-based ET model are not meaningless. The limited availability of high-quality LST images remains an obstacle to continuous daily ET estimation because of the effects of clouds on thermal remote sensing. In contrast, the soil evaporation parameterizations that were formulated in this section could still be used to solve $\mathrm{LE}_{\mathrm{s}}$ when the LST is unavailable through the use of the soil surface energy balance equation (i.e., $H_{\mathrm{s}}\left(T_{\mathrm{s}}\right)+\mathrm{LE}_{\mathrm{s}}\left(T_{\mathrm{s}}\right)+G=R_{\mathrm{ns}}$ ), in which only $T_{\mathrm{S}}$ is unknown. Thus, the method that was proposed here shows potential in diagnostic or process-based ET models.

\subsection{Evaluating the soil evaporation parameterizations that used the atmospheric humidity}

In this section, we establish and evaluate the relationships between the relative evaporation and the surface dryness indices $\left(\mathrm{SDI}_{3}\right.$ and $\left.\mathrm{SDI}_{4}\right)$ that mainly use the atmospheric humidity and test the fitness of the soil evaporation parameterizations (Eqs. (24)-(27)) that are based on the potential evaporation and relative evaporation concepts to the observation data. The calibrated parameters, RMSEs and biases of the predicted relative evaporation are shown in Tables 9 and 10. For $\mathrm{SDI}_{3}$, the results at both sites indicated that $\mathrm{LE}_{\mathrm{s}} / \mathrm{LE}_{\mathrm{s} \_\mathrm{pm}}=\mathrm{fun}\left(\mathrm{SDI}_{3}\right)$ performed better than 

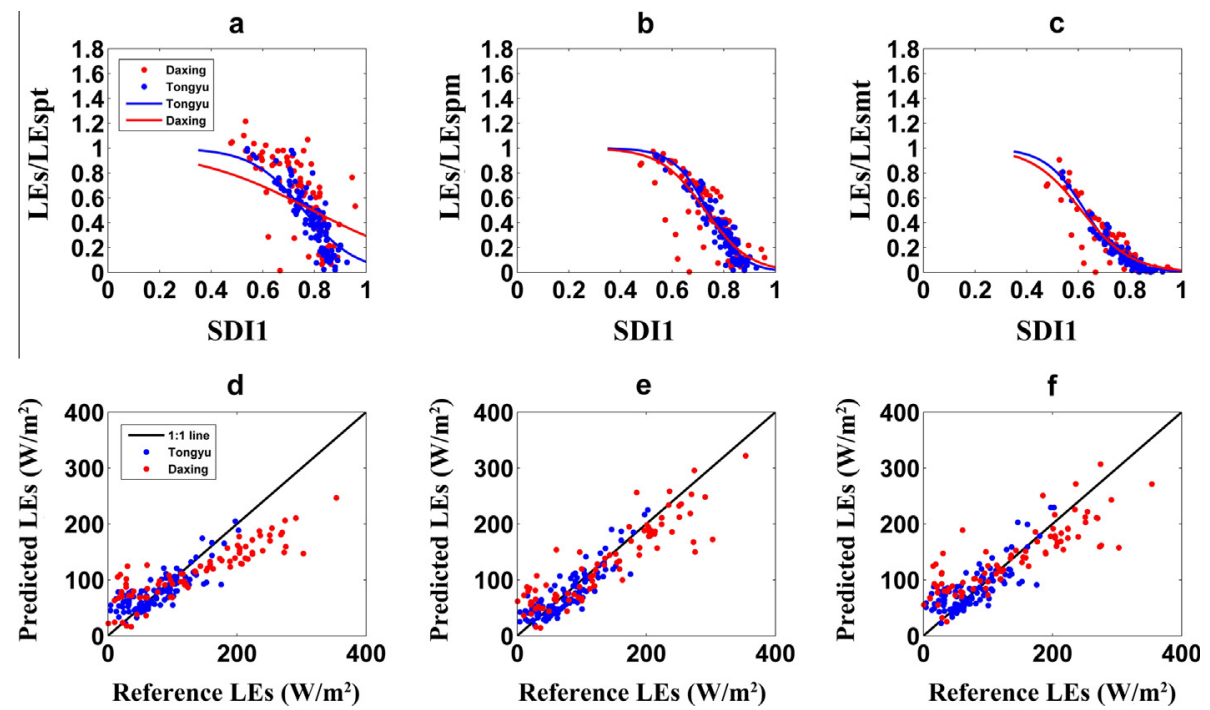

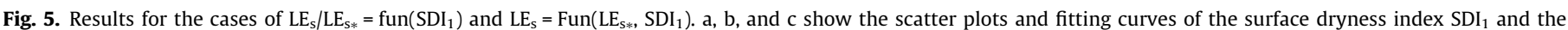

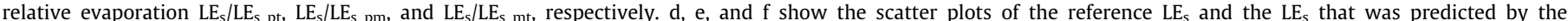
parameterizations of $\mathrm{LE}_{\mathrm{s}}=\mathrm{Fun}\left(\mathrm{LE}_{\mathrm{s}_{-} \mathrm{pt}}, \mathrm{SDI}_{1}\right), \mathrm{LE}_{\mathrm{s}}=\mathrm{Fun}\left(\mathrm{LE}_{\mathrm{s}_{-} \mathrm{pm}}, \mathrm{SDI}_{1}\right)$, and $\mathrm{LE}_{\mathrm{s}}=\mathrm{Fun}\left(\mathrm{LE}_{\mathrm{s}_{\_} \mathrm{mt}}, \mathrm{SDI}_{1}\right)$, respectively.

a

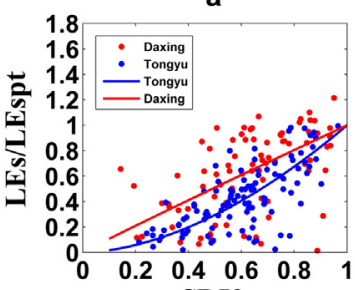

SDI2

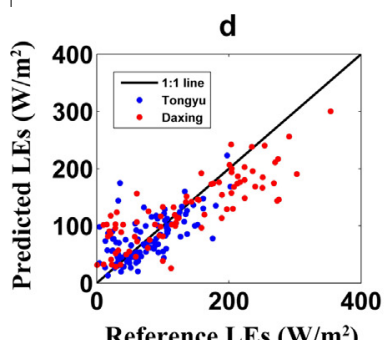

b

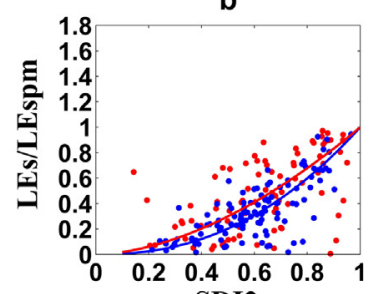

SDI2

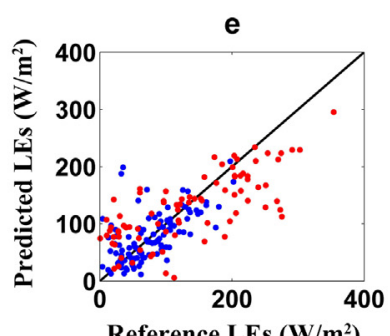

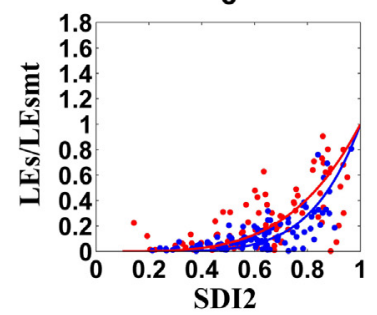

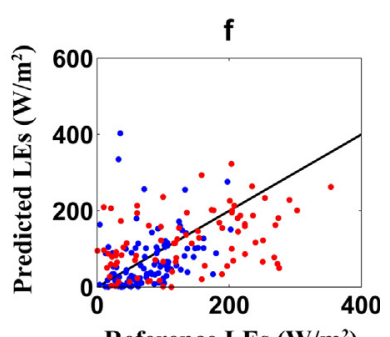

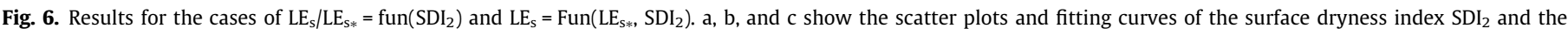

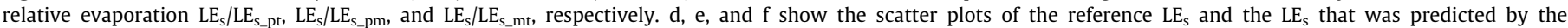
parameterizations of $\mathrm{LE}_{\mathrm{s}}=\mathrm{Fun}\left(\mathrm{LE}_{\mathrm{s}_{-} \mathrm{pt}}, \mathrm{SDI}_{2}\right), \mathrm{LE}_{\mathrm{s}}=\mathrm{Fun}\left(\mathrm{LE}_{\mathrm{s}_{-} \mathrm{pm}}, \mathrm{SDI}_{2}\right)$, and $\mathrm{LE}_{\mathrm{s}}=\mathrm{Fun}\left(\mathrm{LE}_{\mathrm{s}_{-} \mathrm{mt}}, \mathrm{SDI}_{2}\right)$, respectively.

Table 9

Evaluation of the fitting of the relative evaporation curve and its usefulness in estimating the soil evaporation. $\mathrm{SDI}_{3}$ was used as the surface dryness index.

\begin{tabular}{|c|c|c|c|c|c|}
\hline & $\begin{array}{l}\text { Relative evaporation } \\
\text { parameterizations }\end{array}$ & $a$ & $b$ & RMSE & BIAS \\
\hline Daxing & $\begin{array}{l}\mathrm{LE}_{\mathrm{s}} / \mathrm{LE}_{\mathrm{s} \_\mathrm{pt}}=\text { fun }\left(\mathrm{SDI}_{3}\right) \\
\mathrm{LE}_{\mathrm{s}} / \mathrm{LE}_{\mathrm{s} \_\mathrm{pm}}=\text { fun }\left(\mathrm{SDI}_{3}\right)\end{array}$ & $\begin{array}{l}0.0215 \\
0.0122\end{array}$ & $\begin{array}{l}5.07 \\
7.02\end{array}$ & $\begin{array}{l}0.284 \\
0.228\end{array}$ & $\begin{array}{l}-0.002 \\
0.004\end{array}$ \\
\hline Tongyu & $\begin{array}{l}\mathrm{LE}_{\mathrm{s}} / \mathrm{LE}_{\mathrm{s}_{\mathrm{Spt}}}=\text { fun }\left(\mathrm{SDI}_{3}\right) \\
\mathrm{LE}_{\mathrm{s}} / \mathrm{LE}_{\mathrm{s}_{-} \mathrm{pm}}=\text { fun }\left(\mathrm{SDI}_{3}\right) \\
\mathrm{LE}_{\mathrm{s}} \text { parameterizations }\end{array}$ & $\begin{array}{l}0.0100 \\
0.0535\end{array}$ & $\begin{array}{l}4.23 \\
5.80\end{array}$ & $\begin{array}{l}0.222 \\
0.181 \\
\text { RMSE } \\
\left(\mathrm{W} / \mathrm{m}^{2}\right)\end{array}$ & $\begin{array}{l}-0.002 \\
0.002 \\
\text { BIAS } \\
\left(\mathrm{W} / \mathrm{m}^{2}\right)\end{array}$ \\
\hline Daxing & 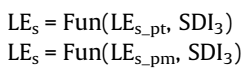 & & & $\begin{array}{l}58.6 \\
66.4\end{array}$ & $\begin{array}{l}-6.0 \\
-4.8\end{array}$ \\
\hline Tongyu & $\begin{array}{l}\mathrm{LE}_{\mathrm{s}}=\operatorname{Fun}\left(\mathrm{LE}_{\mathrm{s} \_\mathrm{pt}}, \mathrm{SDI}_{3}\right) \\
\mathrm{LE}_{\mathrm{s}}=\operatorname{Fun}\left(\mathrm{LE}_{\mathrm{s} \_\mathrm{pm}}, \mathrm{SDI}_{3}\right)\end{array}$ & & & $\begin{array}{l}41.2 \\
42.2\end{array}$ & $\begin{array}{l}3.7 \\
5.7\end{array}$ \\
\hline
\end{tabular}

Table 10

Evaluation of the fitting of the relative evaporation curve and its usefulness in estimating the soil evaporation. $\mathrm{SDI}_{4}$ was used as the surface dryness index.

\begin{tabular}{|c|c|c|c|c|}
\hline & $\begin{array}{l}\text { Relative evaporation } \\
\text { parameterizations }\end{array}$ & $\beta$ & RMSE & BIAS \\
\hline Daxing & $\begin{array}{l}\mathrm{LE}_{\mathrm{s}} / \mathrm{LE}_{\mathrm{s} \_\mathrm{pt}}=\text { fun }\left(\mathrm{SDI}_{4}\right) \\
\mathrm{LE}_{\mathrm{s}} / \mathrm{LE}_{\mathrm{s} \_\mathrm{pm}}=\text { fun }\left(\mathrm{SDI}_{4}\right)\end{array}$ & $\begin{array}{l}1.452 \\
2.644\end{array}$ & $\begin{array}{l}0.309 \\
0.285\end{array}$ & $\begin{array}{l}0.027 \\
0.020\end{array}$ \\
\hline Tongyu & $\begin{array}{l}\mathrm{LE}_{\mathrm{s}} / \mathrm{LE}_{\mathrm{s}_{\mathrm{p}} \mathrm{pt}}=\text { fun }\left(\mathrm{SDI}_{4}\right) \\
\mathrm{LE}_{\mathrm{s}} / \mathrm{LE}_{\mathrm{s}_{-} \mathrm{pm}}=\text { fun }\left(\mathrm{SDI}_{4}\right)\end{array}$ & $\begin{array}{l}4.097 \\
5.474\end{array}$ & $\begin{array}{l}0.243 \\
0.203\end{array}$ & $\begin{array}{l}0.005 \\
-0.005\end{array}$ \\
\hline & $\mathrm{LE}_{\mathrm{s}}$ parameterizations & & $\begin{array}{l}\text { RMSE (W/ } \\
\left.\mathrm{m}^{2}\right)\end{array}$ & $\begin{array}{l}\text { BIAS (W/ } \\
\left.\mathrm{m}^{2}\right)\end{array}$ \\
\hline Daxing & $\begin{array}{l}\mathrm{LE}_{\mathrm{s}}=\operatorname{Fun}\left(\mathrm{LE}_{\mathrm{s}-\mathrm{pt}}, \mathrm{SDI}_{4}\right) \\
\mathrm{LE}_{\mathrm{s}}=\operatorname{Fun}\left(\mathrm{LE}_{\mathrm{S}_{-} \mathrm{pm}}, \mathrm{SDI}_{4}\right)\end{array}$ & & $\begin{array}{l}62.8 \\
77.4\end{array}$ & $\begin{array}{l}-3.0 \\
-4.0\end{array}$ \\
\hline Tongyu & $\begin{array}{l}\mathrm{LE}_{\mathrm{s}}=\operatorname{Fun}\left(\mathrm{LE}_{\mathrm{s} \text { pt }}, \mathrm{SDI}_{4}\right) \\
\mathrm{LE}_{\mathrm{s}}=\operatorname{Fun}\left(\mathrm{LE}_{\mathrm{s}_{-} \mathrm{pm}}, \mathrm{SDI}_{4}\right)\end{array}$ & & $\begin{array}{l}46.1 \\
49.2\end{array}$ & $\begin{array}{l}3.0 \\
-0.3\end{array}$ \\
\hline
\end{tabular}


$\mathrm{LE}_{\mathrm{s}} / \mathrm{LE}_{\mathrm{S} \_\mathrm{pt}}=$ fun $\left(\mathrm{SDI}_{3}\right)$. Similar results were found for $\mathrm{SDI}_{4}$. In addition, $\mathrm{SDI}_{3}$ was always better than $\mathrm{SDI}_{4}$ when modeling the same $\mathrm{LE}_{\mathrm{s}} / \mathrm{LE}_{\mathrm{s} *}$ at the same site (Tables 9 and 10). Both surface dryness indices include the factor $e_{*}\left(t_{\mathrm{a}}\right)-e_{\mathrm{a}}$ to indicate the water availability of the surface; however, compared to $\mathrm{SDI}_{4}, \mathrm{SDI}_{3}$ is a normalized factor that considers both the atmospheric forcing and the energy balance effect when indicating the surface dryness.

The evaporation was estimated by using the fitted curves of the relative evaporation (Figs. 7 and 8). Although $\mathrm{LE}_{\mathrm{s}} / \mathrm{LE}_{\mathrm{s}_{-} \mathrm{pm}}=\mathrm{fun}\left(\mathrm{SDI}_{4}\right)$ had better fitting results than $\mathrm{LE}_{\mathrm{s}} / \mathrm{LE}_{\mathrm{s}_{-} \mathrm{pt}}=\mathrm{fun}\left(\mathrm{SDI}_{4}\right)$ in terms of relative evaporation, the accuracy of estimating the evaporation with this curve proved to be poorer than $\mathrm{LE}_{\mathrm{S}}=\mathrm{Fun}\left(\mathrm{LE}_{\mathrm{s} \_\mathrm{pt}}, \mathrm{SDI}_{4}\right)$ at the Daxing site. However, the accuracies of using $\mathrm{LE}_{\mathrm{s}_{-} \mathrm{pt}}$ and $\mathrm{LE}_{\mathrm{s}_{-} \mathrm{pm}}$ in estimating the soil evaporation were quite close when $\mathrm{SDI}_{3}$ was used.
Although the PT approach is the simplest formulation to estimate the potential evaporation, $\mathrm{LE}_{\mathrm{s} \text { pt }}$ is a useful potential evaporation index to estimate the soil evaporation. The PT approach represents the lower limit of potential evaporation because this method does not consider the drying power of the air. As a result, the sensitivity of $\mathrm{LE}_{\mathrm{s}}$ to the error of $\mathrm{LE}_{\mathrm{S}} / \mathrm{LE}_{\mathrm{s} \_\mathrm{pt}}$ is also the smallest. In addition, the parameterization that used $L_{\mathrm{s} \_\mathrm{pt}}$ to estimate $\mathrm{LE}_{\mathrm{s}}$ could be as sound as that with $\mathrm{LE}_{\mathrm{s} \_ \text {pm }}$, especially when $\mathrm{SDI}_{3}$ was used because the surface dryness indices in this study include the effect of the drying power of the air.

Table 11 shows the relative differences in the RMSEs of $\mathrm{LE}_{\mathrm{s}}$ from the parameterizations that incorporated the LST in the surface dryness indices and those that did not. For example, the RMSEs of $\mathrm{LE}_{\mathrm{s}}=\mathrm{Fun}\left(\mathrm{LE}_{\mathrm{s} \_\mathrm{pm}}, \mathrm{SDI}_{1}\right)$ were $38.9 \%$ and $49.5 \%$ smaller than those of $\mathrm{LE}_{\mathrm{s}}=\mathrm{Fun}\left(\mathrm{LE}_{\mathrm{s} \_\mathrm{pm}}, \mathrm{SDI}_{3}\right)$ at the Daxing site and Tongyu site,
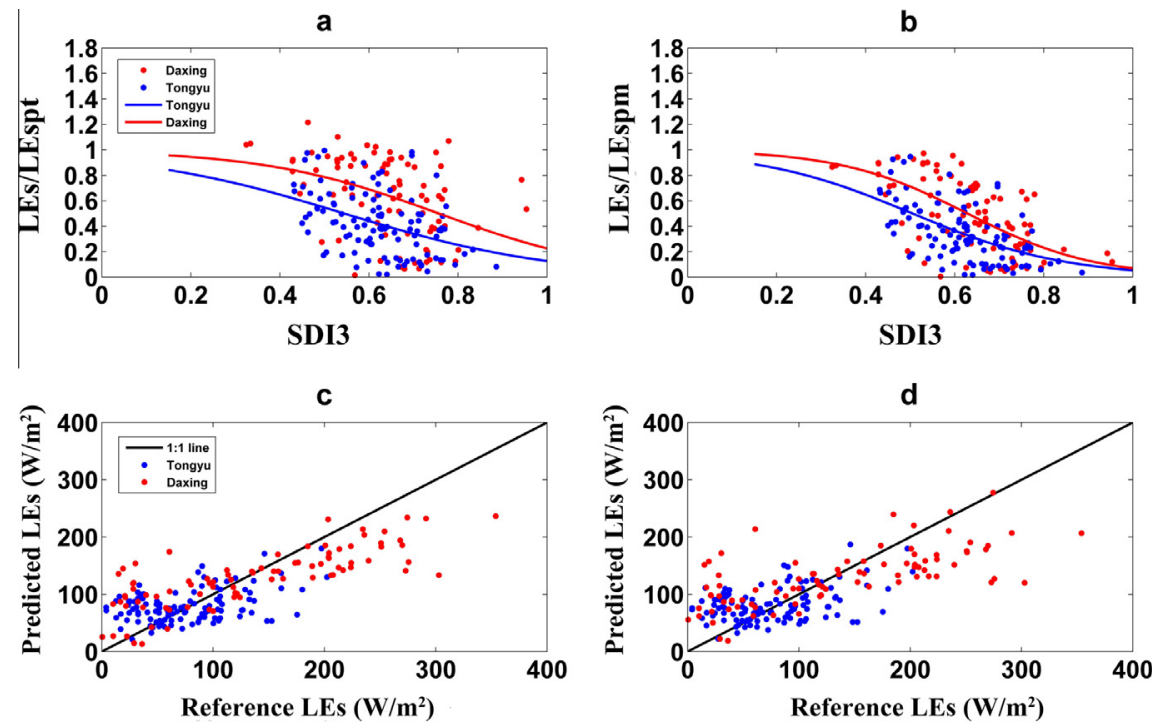

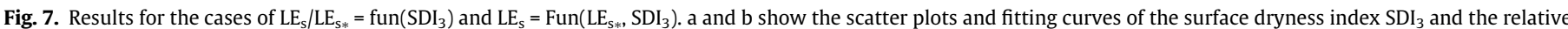

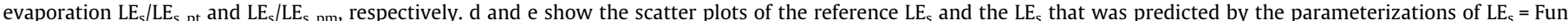
$\left(\mathrm{LE}_{\mathrm{s}_{-} \mathrm{pt}}, \mathrm{SDI}_{3}\right)$ and $\mathrm{LE}_{\mathrm{s}}=\mathrm{Fun}\left(\mathrm{LE}_{\mathrm{s}_{-} \mathrm{pm}}, \mathrm{SDI}_{3}\right)$, respectively.

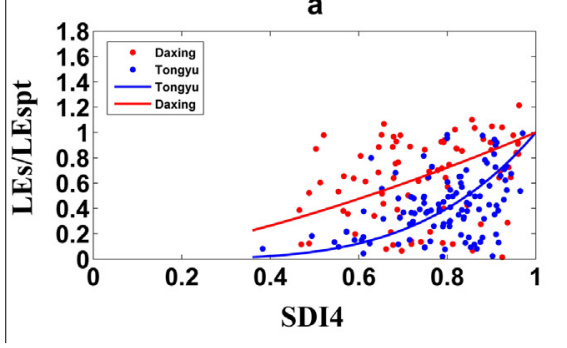

C

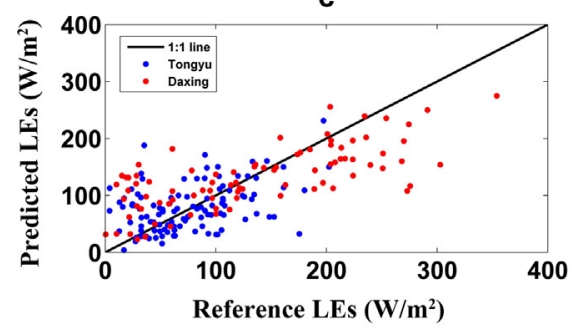

b

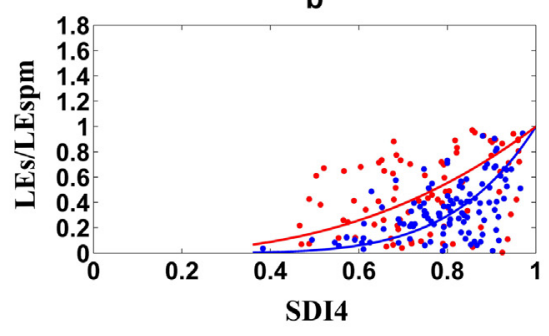

d

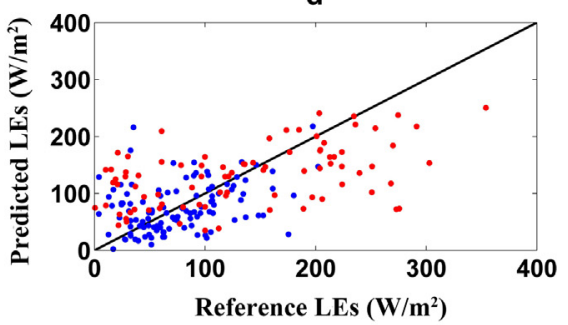

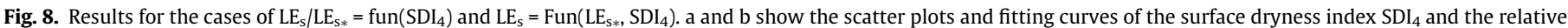

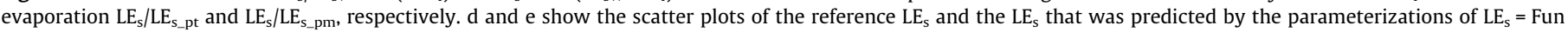
$\left(\mathrm{LE}_{\mathrm{s} \_\mathrm{pt}}, \mathrm{SDI}_{4}\right)$ and $\mathrm{LE}_{\mathrm{s}}=\mathrm{Fun}\left(\mathrm{LE}_{\mathrm{s} \_\mathrm{pm}}, \mathrm{SDI}_{4}\right)$, respectively. 
Table 11

Relative differences in the RMSEs of $\mathrm{LE}_{\mathrm{s}}$ from different parameterizations.

\begin{tabular}{|c|c|c|c|c|}
\hline & \multicolumn{4}{|c|}{ Relative differences in $\mathrm{LE}_{\mathrm{s}}$ RMSEs (\%) } \\
\hline & \multicolumn{2}{|l|}{ PT } & \multicolumn{2}{|l|}{ PM } \\
\hline & $\mathrm{SDI}_{1}$ vs. $\mathrm{SDI}_{3}$ & $\mathrm{SDI}_{2}$ vs. $\mathrm{SDI}_{4}$ & $\mathrm{SDI}_{1}$ vs. $\mathrm{SDI}_{3}$ & $\mathrm{SDI}_{2}$ vs. $\mathrm{SDI}_{4}$ \\
\hline Daxing & -5.1 & -18.5 & -38.9 & -21.6 \\
\hline Tongyu & -38.6 & -26.2 & -49.5 & -23.0 \\
\hline
\end{tabular}

respectively. This result indicates that incorporating the soil temperature in the surface dryness indices had improved the soil evaporation estimation. However, the parameterizations that used $\mathrm{SDI}_{3}$ or $\mathrm{SDI}_{4}$ still performed quite well (Tables 9 and 10). In addition, such formulations that used the atmospheric humidity could be used with a canopy conductance model to estimate the total ET when LST data were not available or when the LST was not considered in the surface energy balance.

\subsection{Evaluating the soil evaporation parameterizations that were based} on the soil surface resistance and near-surface soil moisture

Diagnostic and process-based ET models usually use the concept of soil surface resistance $\left(r_{\mathrm{ss}}\right)$ to consider the degree of unsaturation of the soil water. $\mathrm{LE}_{\mathrm{s}}$ is estimated by the mass transfer equation and $r_{\mathrm{ss}}$ is simulated by an exponential function of the soil moisture (Sellers et al., 1992). In this paper, $r_{\mathrm{ss}}$ includes both the effects of the un-saturation of the soil water on the surface water vapor pressure $e_{*}\left(T_{\mathrm{s}}\right)$ and the resistance of the soil surface to water vapor:

$L E_{s}=\frac{\rho c_{p}}{\gamma} \frac{e_{s}\left(T_{s}\right)-e_{a}}{r_{s s}+r_{s}+r_{a}}$
$\ln \left(r_{s s}\right)=a_{0}-a_{1} \cdot s m$

where $s m=s w c / s w c_{\text {sat }} . s w c$ and $s w c_{\text {sat }}$ are the actual and saturated soil water content, respectively.

We fit the curve of $\ln \left(r_{\mathrm{ss}}\right)$ to $\mathrm{sm}$ and then evaluated the parameterization of $\mathrm{LE}_{\mathrm{s}}=\operatorname{Fun}\left(r_{\mathrm{ss}}, \mathrm{sm}\right)$. Fig. 9 shows that the scatter points were divided into two categories approximately by the line $s m=0.31$ for the Daxing site. The time when $s m$ was smaller than 0.31 at the Daxing site mainly lay in two periods, i.e., DOY 1-58 and DOY 286-365. A similar phenomenon was found at the Tongyu site when all the LST data ( $\mathrm{qc}=0$ and $\mathrm{qc}>0$ ) were used (not shown in Fig. 9). However, the data points when $s m$ was small were basically ruled out because the LST at such timings was not qualified at the Tongyu site (see Figs. 3 and 4). In general, the timings of the points when $s m$ was small at both sites mainly lay in winter and spring, when soil moisture would experience freezing and thawing cycles because of the cold weather. The relationships between the soil surface resistance and soil moisture would therefore be different under different weather conditions. Thus, we fit the curve into separate groups at the Daxing site. The parameters and statistical results at both sites are shown in Table 12 and Fig. 9. a
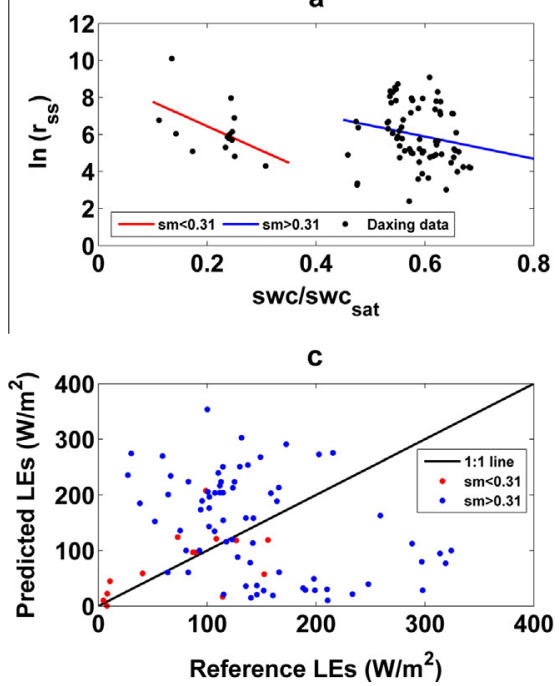

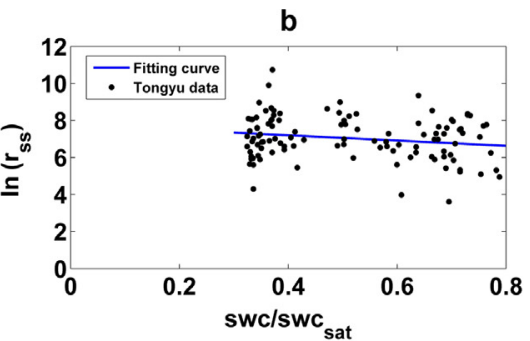

d

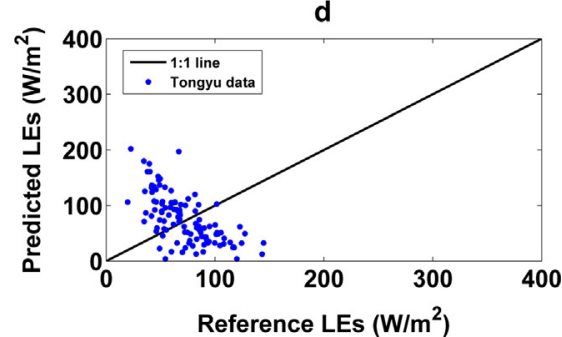

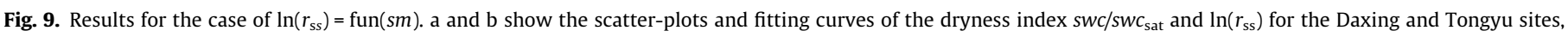

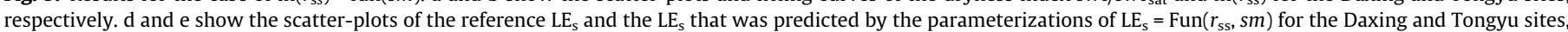
respectively.

Table 12

Prediction accuracies of the soil surface resistance and the soil evaporation.

\begin{tabular}{|c|c|c|c|c|c|}
\hline & $r_{\mathrm{ss}}$ parameterizations & $a_{0}$ & $a_{1}$ & RMSE & BIAS \\
\hline \multirow[t]{2}{*}{ Daxing } & $\begin{array}{l}\ln \left(r_{s s}\right)=\text { fun }(s m) \\
s m<0.31\end{array}$ & 9.08 & 13.18 & 1.212 & 0.005 \\
\hline & $\begin{array}{l}\ln \left(r_{\mathrm{ss}}\right)=\text { fun }(s m) \\
0.31<\mathrm{sm}<1\end{array}$ & 9.48 & 6.00 & 1.551 & 0.030 \\
\hline \multirow[t]{2}{*}{ Tongyu } & $\ln \left(r_{\mathrm{ss}}\right)=\mathrm{fun}(\mathrm{sm})$ & 8.04 & 1.69 & 1.153 & -0.02 \\
\hline & $\mathrm{LE}_{\mathrm{s}}$ parameterizations & & & $\operatorname{RMSE}\left(\mathrm{W} / \mathrm{m}^{2}\right)$ & $\operatorname{BIAS}\left(\mathrm{W} / \mathrm{m}^{2}\right)$ \\
\hline Daxing & $\mathrm{LE}_{\mathrm{s}}=\operatorname{Fun}\left(r_{\mathrm{ss}}, s m\right)$ & & & 123.3 & -2.3 \\
\hline Tongyu & $\mathrm{LE}_{\mathrm{s}}=\operatorname{Fun}\left(r_{\mathrm{ss}}, \mathrm{sm}\right)$ & & & 63.8 & -3.8 \\
\hline
\end{tabular}


The RMSEs of $\ln \left(r_{\mathrm{ss}}\right)$ in the three cases at both sites exceeded 1 , with the maximum value being 1.551 , which indicates that $r_{\mathrm{ss}}$ and therefore the estimated $L_{s}$ could be several times greater than the actual values. The RMSEs in $\mathrm{LE}_{\mathrm{s}}$ from the parameterization of $\mathrm{LE}_{\mathrm{s}}=\operatorname{Fun}\left(r_{\mathrm{ss}}, \mathrm{sm}\right)$ were $203.7 \%$ greater and $199.5 \%$ greater than those from the parameterization of $\mathrm{LE}_{\mathrm{s}}=\mathrm{Fun}\left(\mathrm{LE}_{\mathrm{s} \_\mathrm{pm}}, \mathrm{SDI}_{1}\right)$ at the Daxing and Tongyu sites, respectively. At the same time, the RMSEs in $\mathrm{LE}_{\mathrm{s}}$ from the parameterization of $\mathrm{LE}_{\mathrm{s}}=\operatorname{Fun}\left(r_{\mathrm{ss}}, \mathrm{sm}\right)$ were $110.4 \%$ greater and $54.9 \%$ greater than those from the parameterization of $\mathrm{LE}_{\mathrm{s}}=\mathrm{Fun}\left(\mathrm{LE}_{\mathrm{s} \_\mathrm{pt}}, \mathrm{SDI}_{3}\right)$ at the Daxing and Tongyu sites, respectively.

The parameterization of $\mathrm{LE}_{\mathrm{s}}=\mathrm{Fun}\left(r_{\mathrm{ss}}, \mathrm{sm}\right)$ performed worse than those of $\mathrm{LE}_{\mathrm{s}}=\mathrm{Fun}\left(\mathrm{LE}_{\mathrm{s} \_\mathrm{pm}}, \mathrm{SDI}_{1}\right)$ and $\mathrm{LE}_{\mathrm{s}}=\mathrm{Fun}\left(\mathrm{LE}_{\mathrm{s} \_\mathrm{pt}}, \mathrm{SDI}_{3}\right)$, which indicates that accurate estimations were difficult to achieve even with the soil moisture measurements. One of the drawbacks of the parameterization of $\mathrm{LE}_{\mathrm{s}}=\mathrm{Fun}\left(r_{\mathrm{ss}}, s m\right)$ was that the soil moisture at $2 \mathrm{~cm}$ and $5 \mathrm{~cm}$ may have been unable to represent the surface moisture conditions because of the decoupling effect of the soil moisture at different depths (Capehart and Carlson, 1997) and because the soil surface energy balance is more strongly coupled to the surface's (several millimeters) moisture conditions than at deeper layers (2 cm and $5 \mathrm{~cm}$ ) (Kustas et al., 2003).

\section{Conclusions}

In this study, we evaluated 11 parameterizations of soil evaporation at near-instantaneous scales at two semi-humid and semiarid crop sites, where detailed measurements of heat fluxes and atmospheric conditions were available. The relationships between the relative evaporation and SDI and their usefulness in estimating soil evaporation were studied.

Incorporating the soil temperature in the surface dryness indices improved the soil evaporation estimation. However, the parameterizations that used the LST-based potential evaporation index sometimes produced less accurate soil evaporation values. Therefore, the soil temperature should be used in the surface dryness indices instead of the potential evaporation indices when estimating soil evaporation.

The evaporation that was estimated by using the fitted curve of the relative evaporation, which used the air humidity, showed reasonable results for the potential evaporation indices that were calculated by both the PT approach and the Penman equation. The PT approach represented the lower limit of potential evaporation, and the sensitivity of $\mathrm{LE}_{\mathrm{s}}$ to the errors of $\mathrm{LE}_{\mathrm{s}} / \mathrm{LE}_{\mathrm{s} \_\mathrm{pt}}$ was also the smallest. In addition, the parameterization of $\mathrm{LE}_{\mathrm{s}}=\mathrm{Fun}\left(\mathrm{LE}_{\mathrm{s} \_\mathrm{pt}}, \mathrm{SDI}_{3}\right)$ was as sound as that of $\mathrm{LE}_{\mathrm{S}}=\mathrm{Fun}\left(\mathrm{LE}_{\mathrm{s} \_\mathrm{pm}}, \mathrm{SDI}_{3}\right)$ because the dryness indices in this study included the effect of the drying power of the air. In contrast, the RMSEs in $\mathrm{LE}_{\mathrm{s}}$ from the parameterization of $\mathrm{LE}_{\mathrm{s}}=\operatorname{Fun}\left(r_{\mathrm{ss}}, \mathrm{sm}\right)$ were much larger than those from the cases that used atmospheric humidity data at both sites.

The surface dryness indices that considered the surface energy balance $\left(\mathrm{SDI}_{1}, \mathrm{SDI}_{3}\right)$ were generally better than those that only used the water vapor deficits $\left(\mathrm{SDI}_{2}, \mathrm{SDI}_{4}\right)$ for the same potential evaporation index at the same site, however, the latter indices required less data and were easier to use. Our study indicated that the potential evaporation indices that were based on the Penman equation were the most useful and robust.

\section{Acknowledgements}

Our research was jointly funded by the National Key Project for Research and Development (No. 2016YFC0501605), the National Key Project for Basic Research (973) (No. 2015CB452705), the Key Project of the National Natural Science Foundation of China (No. 41430861) and the National Natural Science Foundation of
China (No. 40871198). The MODIS data were downloaded from the NASA Goddard Space Flight Center (http://ladsweb.nascom.nasa.gov/data/). The CEOP/EOP-3 and CEOP/EOP-4 data (http://www. ceop.net/) were collected and provided by the "Predictive Study of Aridification in Northern China in association with Life-supporting Environment Changes" projects, which was funded by the National Key Basic Research Development Program G1999043404. The data from the Daxing station were provided by the Cold and Arid Regions Science Data Center at Lanzhou.

\section{References}

Agam, N. et al., 2010. Application of the Priestley-Taylor approach in a two-source surface energy balance model. J. Hydrometeorol. 11 (1), 185-198.

Bouchet, R., 1963. Evapotranspiration reelle et potentielle, significantion climatique, vol. 62. IAHS Publ., pp. 134-142.

Brutsaert, W., 1982. Evaporation into the Atmosphere. D. Reidel Publishing Company.

Brutsaert, W., Stricker, H., 1979. Advection-aridity approach to estimate actual regional evapotranspiration. Water Resour. Res. 15 (2), 443-450.

Capehart, W.J., Carlson, T.N., 1997. Decoupling of surface and near-surface soil water content: a remote sensing perspective. Water Resour. Res. 33 (6), 13831395.

Colaizzi, P.D. et al., 2012. Two-source energy balance model estimates of evapotranspiration using component and composite surface temperatures. Adv. Water Resour. 50, 134-151.

Colaizzi, P.D., Schneider, A.D., Evett, S.R., Howell, T.A., 2004. Comparison of SDI LEPA, and spray irrigation performance for grain sorghum. Trans. ASAE 47 (5) 1477-1492.

Crago, R., Crowley, R., 2005. Complementary relationships for near-instantaneous evaporation. J. Hydrol. 300 (1-4), 199-211.

Dekkers, A., Aarts, E., 1991. Global optimization and simulated annealing. Math Program. 50 (3), 367-393.

Fisher, J.B., Tu, K.P., Baldocchi, D.D., 2008. Global estimates of the land-atmosphere water flux based on monthly AVHRR and ISLSCP-II data, validated at 16 FLUXNET sites. Rem. Sens. Environ. 112 (3), 901-919.

Gan, G.J., Gao, Y.C., 2015. Estimating time series of land surface energy fluxes using optimized two source energy balance schemes: model formulation, calibration, and validation. Agr. For. Meteorol. 208, 62-75.

Garcia, M. et al., 2013. Actual evapotranspiration in drylands derived from in-situ and satellite data: assessing biophysical constraints. Rem. Sens. Environ. 131 $103-118$.

Granger, R.J., 1989a. A complementary relationship approach for evaporation from nonsaturated surfaces. J. Hydrol. 111 (1-4), 31-38.

Granger, R.J., 1989b. An examination of the concept of potential evaporation. J Hydrol. 111 (1-4), 9-19.

Granger, R.J., Gray, D.M., 1989. Evaporation from natural nonsaturated surfaces. J. Hydrol. 111 (1-4), 21-29.

Heusinkveld, B.G., Jacobs, A.F.G., Holtslag, A.A.M., Berkowicz, S.M., 2004. Surface energy balance closure in an arid region: role of soil heat flux. Agr. For. Meteorol. 122 (1-2), 21-37.

Jia, Z.Z., Liu, S.M., Xu, Z.W., Chen, Y.J., Zhu, M.J., 2012. Validation of remotely sensed evapotranspiration over the Hai River Basin, China. J. Geophys. Res.-Atmos. 117.

Kirkpatrick, S., Gelatt, C.D., Vecchi, M.P., 1983. Optimization by simulated annealing. Science 220 (4598), 671-680.

Kool, D. et al., 2014. A review of approaches for evapotranspiration partitioning. Agr For. Meteorol. 184, 56-70.

Kustas, W.P., Bindlish, R., French, A.N., Schmugge, T.J., 2003. Comparison of energy balance modeling schemes using microwave-derived soil moisture and radiometric surface temperature. Water Resour. Res. 39 (2).

Lawrence, D.M., Thornton, P.E., Oleson, K.W., Bonan, G.B., 2007. The partitioning of evapotranspiration into transpiration, soil evaporation, and canopy evaporation in a GCM: Impacts on land-atmosphere interaction. J. Hydrometeorol. 8 (4), $862-880$.

Leuning, R., Zhang, Y.Q., Rajaud, A., Cleugh, H., Tu, K., 2008. A simple surface conductance model to estimate regional evaporation using MODIS leaf area index and the Penman-Monteith equation. Water Resour. Res. 44 (10).

Li, F.Q., Kustas, W.P., Prueger, J.H., Neale, C.M.U., Jackson, T.J., 2005. Utility of remote sensing-based two-source energy balance model under low- and highvegetation cover conditions. J. Hydrometeorol. 6 (6), 878-891.

Liu, S.M., Xu, Z.W., 2013. Multi-Scale Surface Flux and Meteorological Elements Observation Dataset in the Hai River Basin (Daxing Site-Eddy Covariance System). Cold and Arid Regions Science Data Center at Lanzhou.

Liu, S.M., Xu, Z.W., Zhu, Z.L., Jia, Z.Z., Zhu, M.J., 2013. Measurements of evapotranspiration from eddy-covariance systems and large aperture scintillometers in the Hai River Basin, China. J. Hydrol. 487, 24-38.

Long, D., Singh, V.P., 2012. A two-source trapezoid model for evapotranspiration (TTME) from satellite imagery. Rem. Sens. Environ. 121, 370-388.

Merlin, O. et al., 2014. An image-based four-source surface energy balance model to estimate crop evapotranspiration from solar reflectance/thermal emission data (SEB-4S). Agr. For. Meteorol. 184, 188-203. 
Morton, F.I., 1983. Operational estimates of areal evapo-transpiration and their significance to the science and practice of hydrology. J. Hydrol. 66 (1-4), 1-76.

Mu, Q.Z., Zhao, M.S., Running, S.W., 2011. Improvements to a MODIS global terrestrial evapotranspiration algorithm. Rem. Sens. Environ. 115 (8), 1781 1800.

Newman, B.D. et al., 2006. Ecohydrology of water-limited environments: a scientific vision. Water Resour. Res. 42 (6)

Nishida, K., Nemani, R.R., Running, S.W., Glassy, J.M., 2003. An operational remote sensing algorithm of land surface evaporation. J. Geophys. Res.-Atmos. 108 (D9).

Oki, T., Kanae, S., 2006. Global hydrological cycles and world water resources. Science 313 (5790), 1068-1072.

Penman, H.L., 1948. Natural evaporation from open water, bare soil and grass. Proc Roy. Soc. Lon. Ser.-A 193 (1032), 120.

Priestley, C.H.B., Taylor, R.J., 1972. Assessment of surface heat-flux and evaporation using large-scale parameters. Mon. Weather Rev. 100 (2), 81.

Sellers, P.J., Heiser, M.D., Hall, F.G., 1992. Relations between surface conductance and spectral vegetation indexes at intermediate $\left(100 \mathrm{~m}^{2}\right.$ to $\left.15 \mathrm{~km}^{2}\right)$ length scales. J. Geophys. Res.-Atmos. 97 (D17), 19033-19059.

Sun, J., 2013. Study on the Potential of Irrigation Water Saving in Typical Area of Haihe River Basin Master thesis. Graduate University of Chinese Academy of Science.

Thornthwaite, C.W., 1948. An approach toward a rational classification of climate. Geogr. Rev. 38, 55-94.
Trenberth, K.E., Fasullo, J.T., Kiehl, J., 2009. Earth’s global energy budget. Bull. Am. Meteorol. Soc. 90 (3), 311.

Trenberth, K.E., Smith, L., Qian, T.T., Dai, A., Fasullo, J., 2007. Estimates of the global water budget and its annual cycle using observational and model data. J. Hydrometeorol. 8 (4), 758-769.

Tu, G., 2007. Study on land-atmosphere interaction on different underlying surface of semi arid region Ph.D thesis. Graduate University of Chinese Academy of Science.

Twine, T.E. et al., 2000. Correcting eddy-covariance flux underestimates over a grassland. Agr. For. Meteorol. 103 (3), 279-300.

Wagner, W. et al., 2007. Operational readiness of microwave remote sensing of soil moisture for hydrologic applications. Nord Hydrol. 38 (1), 1-20.

Wang, Z.C., Li, Q.S., Li, X.J., Song, C.C., Zhang, G.X., 2003. Sustainable agriculture development in saline-alkali soil area of songnen plain, Northeast China. Chin. Geogr. Sci. 13 (2), 171-174.

Yang, D.W., Sun, F.B., Liu, Z.T., Cong, Z.T., Lei, Z.D., 2006. Interpreting the complementary relationship in non-humid environments based on the Budyko and Penman hypotheses. Geophys. Res. Lett. 33 (18).

Yu, P.J. et al., 2014. Effect of cultivation on dynamics of organic and inorganic carbon stocks in songnen plain. Agron. J. 106 (5), 1574-1582.

Zhang, Y.Q. et al., 2010. Using long-term water balances to parameterize surface conductances and calculate evaporation at 0.05 degrees spatial resolution. Water Resour. Res. 46. 